Canadian

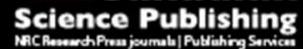

Canadian Journal of Microbiology Revue canadienne de de microbiologie

\title{
Cellular and viral determinants of retroviral nuclear entry
}

\begin{tabular}{|r|l|}
\hline Journal: & Canadian Journal of Microbiology \\
\hline Manuscript ID & cjm-2015-0350.R2 \\
\hline Manuscript Type: & Review \\
\hline Date Submitted by the Author: & 04-Oct-2015 \\
\hline Complete List of Authors: & $\begin{array}{l}\text { Hamid, Faysal Bin; Chung-Ang University, Department of Systems } \\
\text { Biotechnology } \\
\text { Kim, Jinsun; Chung-Ang University, Department of Systems Biotechnology } \\
\text { Shin, Cha-Gyun; Chung Ang University, Department of Systems } \\
\text { Biotechnology }\end{array}$ \\
\hline Keyword: & HIV-1, PIC, nuclear import, TNPO3, 2-LTR \\
\hline \multicolumn{2}{|c}{} \\
\hline
\end{tabular}

SCHOLARONE ${ }^{m}$

Manuscripts 
1 Title: Cellular and viral determinants of retroviral nuclear entry

2 Faysal Bin Hamid ${ }^{1}$, Jinsun Kim ${ }^{1}$, Cha-Gyun Shin ${ }^{1 *}$

$3 \quad{ }^{1}$ Department of Systems Biotechnology, Chung-Ang University, Ansung 456-756, Republic of

$4 \quad$ Korea

5

6

7

8

9

10

11

12

13 *Correspondence:

14 Cha-Gyun Shin, Ph.D.

15 Department of Systems Biotechnology

16 Chung-Ang University

17 Ansung 456-756

18 Republic of Korea

19 Tel: +82-31-670-3067

20 HP: +82-10-9047-6678

21 Fax: +82-31-675-0409

22 E-mail: cgshin@cau.ac.kr

23 


\section{Abstract}

25 Retroviruses must integrate their cDNA into the host genome to generate proviruses. Viral DNA26 protein complexes interact with cellular proteins and produce pre-integration complexes (PICs),

27 which carry the viral genome and cross the nuclear pore channel to enter the nucleus and 28 integrate viral DNA into host chromosomal DNA. If the reverse transcripts fail to integrate, 29 linear or circular DNA species such as 1- and 2-long-terminal-repeats (1-LTRs and 2-LTRs, 30 respectively) are generated. Such complexes encounter numerous cellular proteins in the 31 cytoplasm, which restrict viral infection and protect the nucleus. To overcome host cell defenses,

32 the pathogens have evolved several evasion strategies. Viral proteins often contain nuclear 33 localization signals (NLSs), allowing entry into the nucleus. Among more than 1000 proteins 34 identified as required for HIV infection by RNA interference screening, karyopherins, cleavage 35 and polyadenylation specific factor 6 , and nucleoporins have been predominantly studied. This 36 review discusses current opinions about the synergistic relationship between the viral and 37 cellular factors involved in nuclear import, with focus on the unveiled mysteries of the host38 pathogen interaction, and highlights novel approaches to pinpoint therapeutic targets.

\section{Keywords}

HIV-1, PIC, nuclear import, TNPO3, 2-LTR. 
44

\section{Introduction}

Like other viruses, retroviruses are obligatory intracellular parasites. However, the DNA copies are formed by reverse transcription and integrated into host DNA, which makes them a peculiar group in the microbial world. Retroviruses belong to the Retroviridae family. To meet the requirements of viral replication, from entry to egress, they orchestrate a complex relationship with cellular factors. Several viruses such as HIV-1, influenza A, hepatitis B, and herpes simplex viruses exploit nuclear transport machinery (Cohen et al. 2011). Recent studies on retroviruses, particularly HIV-1, have provided insights on these underlying processes. HIV-1 can invade CD4 $+\mathrm{T}$ cells and thus abate the host immune system (Walker and McMichael 2012). Moreover, integration of the viral genome into CD4+ memory cells and macrophages establishes a latent or chronic infection. To detect invaders, cells express several pattern-recognition receptors (PRRs) and other "sensor" proteins that can detect the pathogen-associated molecular patterns (PAMPs) of viral components, which in turn activate antiviral IFN and other responses (Iwasaki and Medzhitov 2010; Melchjorsen 2013). After overcoming obstacles from the cell membrane to the nucleus (Melchjorsen 2013), viral cDNA associated pre-integration complexes (PICs) enter the nucleus. Then, integrase (IN) facilitates viral DNA integration. If integration does not take place, the PIC self-ligates to form unintegrated DNA called 1- and 2-long terminal repeats (1-LTRs and 2-LTRs, respectively). Recent large-scale siRNA and shRNA screens revealed that over 1000 host proteins participate in a broad array of functions during the HIV-1 replication cycle (Brass et al. 2008; König et al. 2008; Bushman et al. 2009; Borner et al. 2010), although the majority of these hits were probably were false.

During infection, retroviruses bind to specific receptors and coreceptors on the cell surface to penetrate into the cytoplasm and either fuse with these cell surface proteins or are endocytosed 
67 (Overbaugh et al. 2001) (Fig. 1). Once the virions penetrate the host cell, the poorly understood 68 process of uncoating occurs. Uncoating or disassembly, an important early phase of HIV-1 replication, is mainly dependent on capsid stability and determines the nuclear entry of the mature PIC (Moore and Stevenson 2000; Matreyek and Engelman 2013a). The process results in the release of viral RNA from the capsid core into the cytoplasm, where the RNA is reverse transcribed within the reverse transcription complex (RTC) (Fig. 1) (Moore and Stevenson 2000). Upon uncoating, the viral capsid and nucleocapsid, along with the viral reverse transcripts, reverse transcriptase (RT), IN, protease (PR), and viral accessory proteins Vif, Nef, and Vpr, collectively called the reverse transcription complex (RTC), are released. These elements trigger the formation of the PIC, which traverses along the cytoskeleton and enters the nucleus through nuclear pores (Fig. 1). Due to the difficulty of isolating PICs from infected cells, all components of the PIC have not been identified. Additionally, the process of uncoating is still under investigation (Arhel 2010). HIV-1 PICs formed in the cytoplasm are the viral cDNA integration-competent complexes: they transit into the nucleus to form the integrated provirus by utilizing several cellular factors (Stewart 2007).

\section{Canonical nuclear import mechanisms}

Retroviruses generally contain two copies of positive single-stranded RNA and three structural polyproteins (Gag, Pol, Env), which are proteolytically cleaved into smaller proteins (Coffin et al. 1997). After reverse transcription, viral PICs need to be transported to the nucleus. In eukaryotic cells, the cytoplasm and nucleus are interconnected through the nuclear pore complex (NPC), which selectively filters histones, transcription factors, tRNA, rRNA, and mRNA (Stewart 2007). During interphase, the NPC strictly regulates the entry of proteins about $9 \mathrm{~nm}$ in diameter and $45 \mathrm{~nm}$ long by passive diffusion (Pante and Kann 2002). Uncoating is thought to be 
90

91

92

93

94

95

96

97

98

99

100

\section{1}

\section{2} 103

maintained to limit exposure of the viral DNA to cytosolic DNA sensors. Both cytoplasmic dynein and kinesin 1 heavy chain KIF5B silencing delay uncoating, which does not affect reverse transcription but hampers the nuclear import process (Lukic et al. 2014; Fernandez et al. 2015). Interestingly, several imaging-based experiments have shown that a minor amount of CA is associated with the RTC, indicating disassembly of some viral cores in the cytoplasm (Xu et al. 2013; Campbell and Hope 2015). Uncoating may occur when the viral cores pass through the NPC (Lahaye et al. 2013; Campbell and Hope 2015). However, macromolecules ( $>40 \mathrm{kD}$ ) are transported actively by binding to several soluble transport factors called karyopherins, which are specific in their direction of movement. Karyopherin $\beta 1$, also known as importin $\beta$, can recognize and bind to the nuclear localization signals (NLSs) on the cargo via its HEAT repeats (Cingolani et al. 2002). Most of the cytosolic cargoes are imported after binding to the adaptor protein importin $\alpha$. Some proteins such as HIV Rev (Henderson and Percipalle 1997), Tat (Truant and Cullen 1999), and HTLV REX protein (Palmeri and Malim 1999) bind directly to only importin $\beta$. After binding, importin $\beta$ triggers translocation of the trimeric complex into the nucleus through interaction with the cytoplasmic filaments of the NPC (Moroianu et al. 1996; Ball and Ullman 2005; Woodward et al. 2009). Importin $\beta$ can also bind GTP-bound Ran proteins, which supply energy for transport by hydrolysis of GTP into GDP (Stewart 2007; Matreyek and Engelman 2013a). In the nucleus, Ran-GDP is dissociated from the complex and importin $\beta$ and the NLS-containing protein from the adaptor molecule are imported. Afterward, the Ran-GTP concentration gradient generated between the nucleus and cytoplasm causes discharge of both subtypes of importin to the cytoplasm using several exportins, such as Crm1. However, this nuclear import mechanism is subverted by some viruses for import of their PIC, 
112 allowing cDNA to be successfully incorporated into the host genome (Stewart 2007; Hossain et 113 al. 2014; Ali et al. 2015).

114 Interestingly, production of lentiviruses in the infected cells is independent of cell division. 115 Although HIV-1 can produce progeny in both dividing and non-dividing cells (Fig. 2A), simple 116 viruses, including gammaviruses such as murine leukemia virus (MLV) and foamy viruses, 117 cannot infect non-dividing and arrested cells (Patton et al. 2004; Randow et al. 2013). This 118 limitation in infection might be because the viruses require the cell membrane to split during 119 mitosis for incorporation into the nucleus of the daughter cells (Fig. 2B). Alternatively, viral 120 proteins such as MLV CA may produce an unknown factor that blocks infection of non-dividing 121 cells (Goff 2007).

122 HIV-1 evades detection by intrinsic immune factors in the cytoplasm such as apolipoprotein B 123 mRNA editing enzyme, catalytic polypeptide-like 3G (APOBEC3G), tripartite motif-containing 124 protein 5 (TRIM5 $\alpha$ ), tetherin, SAM domain and HD domain-containing protein 1 (SAMHD1), 125 and adenosine deaminase acting on RNA 1 (ADAR1). HIV-1 enters the nucleus through the 126 NPC (Cullen 2006; Huthoff and Towers 2008; Biswas et al. 2012; Chan et al. 2014). If the viral 127 cDNA is arrested in the cytoplasm or is unable to undergo integration either in dividing or non128 diving cells, then different types of unintegrated DNA species (dead end products of reverse 129 transcription) are formed, such as 1-LTR, 2-LTR, and autointegrants (Delelis et al. 2003; Sloan and Wainberg 2011). Among them, 2-LTR circles result from non-homologous end joining and 131 are a nuclear import marker, while 1-LTR results from homologous recombination of one copy 132 of the viral long terminal repeat. In contrast, autointegrants are produced from the processed 3'133 end and any site within the reverse transcribed transcripts (Sloan and Wainberg 2011). 134 Interestingly, MLV and PFV produce circular 2-LTRs in the cytoplasm at the early stage of 
135 infection (Delelis et al. 2003; Serhanv et al. 2004). Moreover, 2-LTR is directly cleaved at the 136 palindromic sequences at the LTR-LTR junction by IN to yield linear cDNA, which contributes 137 to viral replication (Delelis et al. 2005). Using real time PCR, these different forms can be 138 identified and their localization can be determined in "real time" by checking their presence in 139 both cytoplasmic and nuclear fractions.

HIV and other retroviruses utilize the cellular import system for the transport of their own

141 proteins. Different research groups have succeeded in detecting the cellular import systems by 142 genome-wide or yeast two-hybrid screening. However, the roles of their components have not 143 been determined by single or double mutations because viral infection is not inhibited (Cribier et 144 al. 2011; De Iaco et al. 2013; De Houwer et al. 2014; Ali et al. 2015).

Cellular proteins that promote viral protein import

Karyopherins and TNPO3. The main function of karyopherins is to shuttle host mRNA 147 splicing factors, particularly phosphorylated serine/arginine rich proteins (SR proteins) (Lai et al. 148 2001). In HIV-1 infected cells, karyopherins, especially transportin 3 (TNPO3 or TRN-SR2), act 149 as transporters of HIV-1 proteins. Since the identification of TNPO3 as a binding partner of HIV-1 IN through Y2H and pull down assays, the role of TNPO3 in the retrovirus life cycle has 151 been investigated (Christ et al. 2008). Interactions of TNPO3 with the HIV-1 PIC components IN 152 (Christ et al. 2008; De Iaco and Luban, 2011; Larue et al. 2012; Ali et al. 2015) and CA (Valle153 Casuso et al. 2012) were also identified by co-immunoprecipitation and pull-down assays.

154 Different retroviruses show different levels of TNPO3 dependency. For example, simian 155 immunodeficiency virus (SIV), HIV-1, and HIV-2 production declines approximately 15-fold in TNPO3 knockdown (KD) HeLa cells, but FIV and MMLV do not show any sensitivity (Valle- 
157 Casuso et al. 2012). The infection of prototype foamy virus (PFV) is reduced by only 2-fold in 158 TNPO3 KD baby hamster kidney (BHK-21) cells with no effect on late stages, including viral 159 assembly and release (Ali et al. 2015), indicating that replication of PFV is less dependent on 160 TNPO3. Consistently, beta-retroviruses, such as mouse mammary tumor virus (MMTV), can 161 import genetic material via a TNPO3-independent pathway in non-dividing cells and can 162 integrate randomly when using a split genome due to low viral titer (Konstantoulas and Indik 163 2014). Since TNPO3 is the binding partner of IN, low viral production is expected in TNPO3 164 depleted cells.

Due to disagreement regarding possible interaction of importin $\alpha 1$ with $\mathrm{IN}$ in vitro (Woodward et 166 al. 2009; Ao et al. 2010), the contributions of other members of the importin family was 167 investigated in HeLa cells, CD4+ C8166 T cells, and primary macrophages by quantitative RT168 PCR, as they have $50-80 \%$ sequence similarities. The depletion of importin $\alpha 3$ decreases 2 -LTR 169 levels (Ao et al. 2010). Both TNPO3 and importin $\alpha 1$ (Rch1), acting concurrently or 170 independently, are required for successful nuclear import of IN (Levin et al. 2010a). Another 171 homolog, importin 7, was thought to be dispensable in HIV-1 or SIV infected macrophages 172 (Zielske and Stevenson 2005). However, in a cell based co-immunoprecipitation assay, a 173 significant reduction in HIV-1 production was noted in importin 7 knockout cells, indicating that 174 the IN bipartite NLS interacts with importin 7 and not importin 8 in vivo (Ao et al. 2007). 175 Another NLS-containing HIV-1 protein, Rev, is rich in the basic amino acid arginine (instead of 176 lysine) and prefers to interact with transportin and importins 5, 7, and 9 in vitro independent of 177 importin $\alpha$ (Arnold et al. 2006; Hutten et al. 2009). This preference may be dependent on the 178 concentration of each import receptor or competition between import cargo. Additionally, it may 179 be temperature dependent since efficient nuclear import of GST-Rev was observed in digitonin 
180

181

182

183

184

185

186

187

188

189

190

191

192

193

194

195

196

197

198

199

200

201

202

permeabilized cells in the presence of cytosol and Ran wild type (WT) protein at $18^{\circ} \mathrm{C}$ but not in

the absence of cytosol or in the presence of a Ran mutant Q69L, a predominantly GTP-bound form (Arnold et al. 2006). Although this mutant inhibits import via importin $\beta$, importin 5, and transportin, the insensitivity to importin 7 suggests a lower affinity to GTP-bound Ran protein (Arnold et al. 2006). Surprisingly, Rev can induce the separation of preassembled Ran-GTPimportin $\beta$ complexes (Henderson and Percipalle 1997; Arnold et al. 2006), based on competitive binding of Rev and importin $\alpha$ to importin $\beta$. Experimentally, addition of importin $\beta$ binding proteins, such as c-Fos or snurportin, to the complex causes GTP hydrolysis of Ran (Arnold et al. 2006).

Currently, there is debate regarding the stage of the retroviral life cycle in which TNPO3 plays a prominent role. Some research suggests involvement before nuclear entry in the uncoating step, based on in vitro work (Shah et al. 2013), while other studies suggest action during and after the integration step (Cribier et al. 2011; Ocwieja et al. 2011; Schaller et al. 2011; Valle-Casuso et al. 2012; De Iaco et al. 2013). Additionally, Krishnan et al. (2010) claimed that the capsid, and not $\mathrm{IN}$, is the genetic determinant for utilization of TNPO3 during HIV-1 infection because CA mutants with altered capsid stability (e.g., E45A, N74D) are less reliant on TNPO3 for infection. Notably, cyclophilin A (CypA) and tripartite motif 5 (TRIM5) are speculated to have the opposite effect on regulation of CA core stability. CypA destabilizes the CA lattice, accelerating reverse transcription. However, the CA A92E mutant is not sensitive to CypA and causes blockage between the reverse transcription and integration steps (Ylinen et al. 2009; Li et al. 2009). TRIM5 recognizes and destabilizes the CA core, promoting uncoating. Moreover, TNPO3 depletion can alter the sensitivity to inhibition by PF-3450074 (PF74), a small-molecule HIV-1 capsid-targeting compound that mediates capsid lattice destabilization. In the presence of PF74, 
203

204

205

206

207

208

209

210

211

212

213

214

215

216

217

218

219

220

221

222

223

224

225

WT HIV-1 virus has relatively lower provirus production than nuclear import, while the N74D or A105T CA mutants do not (De Iaco and Luban 2011). Therefore much is still unknown about the preferred conditions, timing, and significance of TNPO3-HIV-1 capsid, IN, and potentially the binding to other proteins.

Cleavage and polyadenylation specific factor 6 (CPSF6). In eukaryotes, most mature mRNAs are generated from immature pre-mRNA through endonucleolytic splicing of introns and the addition of a poly (A) tail at the $3^{\prime}$ end (Gruber et al. 2012). Previously, biochemical studies revealed that at least six factors are necessary for this modification to occur efficiently in vitro, including the cleavage and polyadenylation specificity factor (CPSF), the cleavage stimulation factor $(\mathrm{CstF})$, and cleavage factors $\mathrm{I}_{\mathrm{m}}$ and $\mathrm{II}_{\mathrm{m}}\left(\mathrm{CFI}_{\mathrm{m}}\right.$ and $\mathrm{CFII}_{\mathrm{m}}$, respectively). CPSF, poly (A) polymerase, and the nuclear poly (A) binding protein 1 (PABPN1) are involved in polyadenylation (Cardinale et al. 2007). The $3^{\prime}$ end processing factor $\mathrm{CFI}_{\mathrm{m}}$ is a heterodimer composed of a small subunit $(25 \mathrm{kDa})$ and a larger subunit of 59,68 , or $72 \mathrm{kDa}$. Surprisingly, the structure of $\mathrm{CFI}_{\mathrm{m}} 68 \mathrm{kDa}$ (CPSF6) is reminiscent of SR proteins, a family of pre-mRNA splicing factors involved in both constitutive and alternative mRNA splicing (Rüegsegger et al. 1998). CPSF6 is comprised of a proline-rich region flanked by an N-terminal RNA recognition motif (RRM) and an RS-like C-terminal region enriched with RS/D/E dipeptides. Full-length CPSF6 is found only in the nucleus of NIH3T3 cells, while the CPSF6 C-terminal truncated protein (CPSF6-358) is localized to the cytosol, suggesting that the RS-like domain is required for its nuclear transport (Lee et al. 2010).

Price et al. (2014) suggested that CPSF6 binds to the N-terminal region of monomeric HIV-1 CA and accommodates NUP153 only when CA exists in its assembled hexameric form, resulting in both being transported into the nucleus by TNPO3 (Price et al. 2014). Thus, CPSF6 interacts 
226 with intact cores, which are larger than the nuclear pore channel and impedes nuclear entry.

227 However, CA N74D is insensitive to CPSF6-358 restriction by preventing interaction of CA with

228 CPSF6-358 because N74D requires ligand-specific contact and binds to CPSF6 but not NUP153

229 (Price et al. 2012, 2014). The protein interface is conserved both structurally and functionally

230 across diverse lentiviruses including HIV-2, SIVmac, and FIV. Price group proposes that CA-

231 CPSF6 interaction occurs post cellular entry. According to previous data, the CPSF6 residues

$232 \quad 301-327$ are required for restriction in a Trim-fusion assay (fusion of CPSF6 residues 301 to 358

233 to rhesus TRIM5 $\alpha$ ), and conserved residues 313-327 are necessary for function (Lee et al. 2012).

234 PF74 was originally assumed to be a potent inhibitor of CPSF6 due to structural similarities;

235 however, now PF74 is known to interact with the N-terminal domain of CA, completely blocking

236 the CA-CPSF6313-327 interaction (Price et al. 2012).

237 TNPO3 KD can cause mislocalization of CPSF6 in the cytoplasm, inhibiting HIV-1 replication

238 (De Iaco et al. 2013). The role of cytosolic CPSF6 was investigated through different 239 approaches, such as deletion of the CPSF6 NLS and fusion of an additional nuclear export 240 signal. Targeting CPSF6 to the nucleus with a heterologous NLS in the deletion mutant CPSF6241358 can rescue viral infection, suggesting that cytosolic CPSF6 binds to a pocket in CA where 242 N74 and A105 are located and causes delayed disassembly, resulting in stabilization of the 243 capsid cores (De Iaco et al. 2013). The suitable physiological conditions for cytoplasmic CPSF6 244 accumulation remain unknown but may be specific to cell type or stimulus and thus CPSF6 may 245 be required for disassembly only in certain conditions (De Iaco et al. 2013).

246 Although binding efficiency of the D750R/D751R TNPO3 mutant to IN and ASF/SF2 was 247 similar to that seen with the WT, HIV-1 production and sensitivity to CPSF6 were impaired 248 (Maertens et al. 2014). In other experiments, the mutant exhibited slightly reduced affinity for IN 
249 but strong impairment of binding to unphosphorylated ASF/SF2, indicating its lower cargo 250 binding ability (De Houwer et al. 2014).

251 Nucleoporins (NUPs). Several genome-wide RNA interference screening experiments identified 252 numerous NUPs as potential nuclear transport factors for the Retroviridae family, including 253 NUP358/RAN BP2, NUP153, NUP98, and NUP214/CAN (NUP 50, 62, 85, 107, 133, 155,160, 254 210, ELYS, and TRP) (Ebina et al. 2004; Brass et al. 2008; König et al. 2008; Woodward et al. 255 2009; Lee et al. 2010; Zhang et al. 2010; Matreyek and Engelman 2011, 2013a; Di Nunzio et al. 256 2013; Matreyek et al. 2013b). Among them, NUP358 and NUP214 are located exclusively at the 257 cytoplasmic face. NUP153 is found at the nuclear side of the NPC, whereas NUP98 is found on 258 both sides (Walther et al. 2002; Liang and Hetzer 2011). The vertebrate NPC is a 259 macromolecular structure (about $120 \mathrm{MDa}$ ) comprising 30 different NUPs. The transport 260 receptor-cargo complex docks on NUPs, allowing passage across the NPC. Hepatitis B virus, 261 herpes simplex virus, influenza virus, and adenovirus also use NUPs for nuclear entry (Trotman 262 et al. 2001; König et al. 2008, 2010; Copeland et al. 2009; Schmitz et al. 2010), whereas 263 poliovirus and cardiovirus induce modifications of NUPs (Gustin and Sarnow 2001; Porter and 264 Palmenberg 2009). Previous LC-MS/MS studies revealed that KTN1, NUP43, NUP358, NUP45, 265 and NUP54 expression is downregulated on HIV-1 infection while NUP358, NUP98, and TPR 266 expression is upregulated (Chan et al. 2007; Monette et al. 2011).

267 Furthermore, TNPO3 and NUP358/RanBP2 are involved in site selection in chromatin during 268 integration (Ocwieja et al. 2011; Schaller et al. 2011). The absence of either protein alters the 269 preference for integration to regions with lower gene density. Recently, the observed decrease in 270 HIV-1 infectivity and reduced 2-LTR and provirus formation without significant change in early 271 reverse transcribed transcripts in NUP358-depleted cells suggests that Nup358 likely functions 
272 prior to nuclear import but after reverse transcription (Schaller et al. 2011). Previously HIV-1

273 CA, but not SIVmac CA, was shown to compete with the CypA domain of NUP358 for binding 274 to CypA. The interaction between NUP358 and the preassembled CA-NC complex in vitro 275 serves as a docking station for the HIV-1 core (Di Nunzio et al. 2012). Several CA mutants, 276 N57A and N74D, or CypA binding mutants, G89V and P90A, show no or less sensitivity to 277 NUP358 depletion, suggesting that they can be transported via a NUP358/TNPO3-independent 278 route. However, they showed integration site propensity according to the density of transcription 279 units and relevant factors. N57A and N74D integrate into areas with a lower density of 280 transcription units, while G89V and P90A mutants exhibit selectivity to regions with a higher 281 density of transcription units (Schaller et al. 2011).

282 NUP153 is a flexible structure in which the N-terminal region is required for targeting the cargo 283 to the NPC, and the C-terminal FxFG region is important for binding to importin $\alpha / \beta$-bound 284 proteins before release by Ran-GTP binding (Moroianu et al. 1996; Ball and Ullman 2005; 285 Woodward et al. 2009). In addition, the nuclear basket of the NPC is mainly composed of Tpr, 286 which binds to NUP153 at its N-terminal region. HIV-1 replication is significantly reduced in the 287 absence of either Tpr or Nup153 in the cells (Lelek et al. 2015). As expected, NUP153 is 288 required for HIV-1 nuclear import. Tpr is not involved in reverse transcription, nuclear import, 289 or integration, but super-resolution microscopy images show that it is essential for interaction 290 with active genes. Depletion or overexpression of Tpr causes remodeling of chromatin proximal 291 to the NPC by stabilization of LEDGF and changes the integration site preference (Lelek et al. 292 2015). Nup153 binds directly with HIV-1 IN, CA, and Vpr in an importin $\alpha / \beta$ independent 293 manner for import (Varadarajan et al. 2005; Woodward et al. 2009; Di Nunzio et al. 2013), but 294 CA import may be Nup153/TNPO3 dependent (Paulillo et al. 2005; Cardarelli et al. 2012; 
295 Matreyek et al. 2013b). PF74 and/or CPSF6 compete with NUP153 for binding to the HIV-1 CA 296 pocket, thus higher concentrations of PF74 can block HIV-1 infection. However, the dependency 297 of different viruses is not the same. For example, NUP153 KD significantly inhibits RSV 298 (53.7\%) and MPMV (38.7\%) infection but has little to no effect on MLV, FIV, and HIV-1 $299(<4 \%)$. Compared with the 3-5 fold defect in infection observed in either TNPO3 or NUP153 $300 \mathrm{KD}$, double knockdown decreases infection of VSV-G WT virus by 40-fold (Matreyek and 301 Engelman 2011).

302 Interestingly, NUP62 also interacts with HIV-1 IN and binds to chromatin both in the nuclear 303 and chromatin-bound extract of $293 \mathrm{~T}$ cells and T cells (Ao et al. 2012). In pull-down assays, 304 NUP62 binds only with IN and not with MA or Vpr. Although C-terminal residues 358 to 522 305 compete with NUP62 for binding to HIV-1 IN, reduce IN-chromatin complex formation, and 306 decrease HIV-1 infection, the coiled-coil domain of the C-terminal domain of NUP62 assists 307 NUP62-IN association (Ao et al. 2012). NUP62 also binds TRN-SR2, which might provide a 308 waiting spot before transport for host protein-bound cargo complexes. In normal cells, NUP62 309 resides only in the nuclear envelope. During HIV-1 infection, viral Gag, RNA, and Rev resides 310 with NUP62, which mediates shifting to the cytoplasm and plasma membrane, suggesting that 311 NUP62 is likely rearranged as its binding partner, the viral RNA-Gag complex, is exported from 312 the nucleus (Monette et al. 2011).

313 Depletion of NUP68 also impairs the infection capacity of HIV-1 and MLV, but inhibition of the 314 latter may be due to dependence on cell cycle progression as it enters the nucleus during the 315 metaphase step (Di Nunzio et al. 2012). 
316 Despite the postulation that NUP98 is not involved in nuclear import and weakly in HIV-1 317 integration (König et al. 2008), the efficient import of HIV-1 cDNA is blocked in NUP98318 depleted cells, when siRNA is used and when vesicular stomatitis virus matrix protein (VSV M) 319 is used as an inhibitor protein (Ebina et al. 2004). The VSV M interacts with the phenylalanine320 glycine (FG) repeat region of NUP98. Over-expression of NUP98 can rescue the inhibitory 321 effects on infection and decrease 2-LTR formation. Concurrently, the import system is mediated 322 by the importin $\alpha / \beta$ transport pathway (Ebina et al. 2004).

NUP98, NUP358, and other NUPs such as NUP214/CAN and NUP88 are involved in the export of RNA and the leucine-rich nuclear export signal (NES)-containing viral protein Rev from the 325 nucleus, which involves the Crm1 export protein (Zolotukhin and Felber 1999; Hutten and 326 Kehlenbach 2006). Interestingly, NUP214 assists the import of adenovirus DNA through the 327 NPC (Trotman et al. 2001), but no such evidence exists for HIV-1. Therefore, more extensive 328 studies are required to elucidate the interaction of NUPs and their exact role in the import of 329 HIV-1 proteins.

Heat-shock protein 70 (Hsp70). Hsp70 is a member of the cellular chaperone family of proteins 331 present in both the cytoplasm and nucleus. Heat shock proteins are expressed in response to a 332 variety of physiological and environmental insults (Daugaard et al. 2007; Multhoff 2007). There 333 is evidence that Hsp70 promotes the import of HIV-1 PIC into the nucleus (Agostini et al. 2000) 334 in a manner similar to that for Vpr, at least in macrophages (Kogan and Rappaport 2011). Hsp70 335 is required for the transport of karyophilic proteins into the nucleus (Okuno et al. 1993). As expected, their absence from the cytosolic extract retards protein transport, while induction of 337 Hsp70 restores protein transport, indicating the relatedness of Hsp70 with the karyopherin 338 protein family and nuclear import. Previously, in vitro binding assays revealed that the C- 
339 terminal of karyopherin $\alpha$ is required for transcription factor STAT1 and basic type NLS340 containing protein binding, while the N-terminal domain is a "hotspot" for Hsp60 and Vpr 341 binding (Agostini et al. 2000). Furthermore, as Hsp70 cannot bind the HIV-1 MA, which has 342 affinity to karyopherin $\alpha$, the interaction of Hsp70 with karyopherin $\alpha$ likely mediates the 343 interaction between karypherin $\alpha$ and HIV-1 MA, resulting in the formation of a heterotrimeric 344 complex (Agostini et al. 2000).

Lens epithelium-derived growth factor (LEDGF). LEDGF/p75, a ubiquitous nuclear protein, binds ectopic HIV-1 IN in 293T cells (Cherepanov et al. 2003; Liano et al. 2004a, 2004b). A PWWP domain in the N-terminus binds chromatin, acting as a tethering agent of IN to chromatin (Hombrouck et al. 2007). LEDGF/p75 contains a functional SV40-like NLS in its N-terminal domain (148GRKRKAEKQ156) and is transported to the nucleus in an importin $\alpha / \beta$ - and temperature-dependent manner (Maertens et al. 2004). In a transient knockout via siRNA, LEDGF was found to be essential and sufficient for the nuclear transport of HIV-1 IN. Unlike LEDGF, its alternative splice variant, p52, neither binds with nor imports IN. Moreover, an NLS-defective mutation in at least one amino acid (Lys150) position causes abrogation of HIV-1 IN nuclear import (Maertens et al. 2014). Consistently, stable knockout by shRNA perturbs the interaction between HIV-1 IN and LEDGF, thereby preventing nuclear entry, compatible with its roles in tethering IN and chromatin. Comparable levels of 2-LTR observed in both non-dividing and wild type cells indicate that LEDGF can bind tightly to multiple lentiviral INs and tether them to chromatin in an NLS-independent manner. However, LEDGF might be involved in nuclear import in either an NLS-dependent or independent manner. More intense studies are needed to confirm its genuine role in the lentiviral life cycle (Llano et al. 2004a; Levin et al. 2010a, 2011). 
362 To clarify retroviral nuclear shuttling, further understanding is needed regarding the role of 363 myxovirus resistance $2(\mathrm{MX} 2$, also known as MXB), barrier-to-autointegration factor (BAF), and 364 other proteins, especially transcription related proteins and RNA binding proteins, in the host 365 cell. BAF is a $10 \mathrm{kDa}$ protein ubiquitously found in eukaryotic cells (Segura-Totten and Wilson 366 2004). BAF binds directly to dsDNA, lamin A (essential in nuclear structure and chromatin 367 arrangement), transcriptional activators, and retroviral PICs. BAF also binds retroviral MA to 368 become a component of the HIV-1 PIC. BAF dimers have two binding sites for dsDNA and likely stop retroviral DNA from autointegration via IN (Lee and Craigie 1998). As a component 370 of PICs, BAF can bind to DNA and inhibit autointegration after reverse transcription but before 371 and during the integration step (Segura-Totten and Wilson 2004).

372 Like BAF, another nuclear inner membrane protein, emerin (EMD), is necessary for HIV-1 373 infection in non-dividing cells (Jacque and Stevenson 2006). Silencing of EMD in macrophages 374 produces abortive integration into the host chromatin, although nuclear entry of PIC and 375 infection are not interrupted. However, the opposite result is not seen in dividing cells, 376 suggesting that at the end of mitosis, the nuclear envelope is regenerated and EMD may induce 377 chromatin engagement because the binding of HIV-1 RT copies to chromatin is a prerequisite for 378 entry into the nucleus. Consistent with these data, restriction of MLV infection relies on nuclear 379 protein lamina-associated polypeptide 2 (LAP2) but not EMD. Based on the dependency of HIV3801 on both EMD and lamina-associated polypeptide $\alpha(\operatorname{LAP} \alpha)$ for its infection, the functions of 381 these proteins are likely redundant because the malfunction of either can be rescued by the other. 382 Intriguingly, lentiviruses and oncoretroviruses may use LAP $\alpha$ throughout their life cycle, but 383 EMD is required for lentiviruses (Jacque and Stevenson 2006). Moreover, upon viral infection, 384 EMD is phosphorylated, which is dependent on both mitogen-activated protein kinase (MAPK) 
385

386

387

388

389

390

391

392

393

394

395

396

397

398

399

400

401

402

403

404

405

406

and MEK1 kinase (Bukong et al. 2010). Particularly, MAPK binds with the virion and induces

Gag-MA phosphorylation (Cartier et al. 1997; Bukong et al. 2010). Inhibition of these two proteins in macrophages causes a reduction in EMD phosphorylation and viral integration, affecting the viral infection (Bukong et al. 2010). Therefore, these proteins are likely directly or indirectly related to each other and required for HIV-1 PIC import, at least in a cell-specific manner.

\section{Import-mediating viral components}

Gag. In lentiviruses, Gag is one of the essential polyproteins. Gag is cleaved to generate four proteins: MA, CA, NC, and p6 (Coffin et al. 1997). There is debate whether CA is present in the viral PIC or not. Most recently, compartmentalization of CA in the nucleus of infected cells was determined by direct interaction with the FG-repeat enriched NUP153 (Matreyek et al. 2013b).

CA binds with several cellular proteins, including TNPO3, NUP358, NUP153, NUP158, TRIM5 $\alpha$, CPSF6, and Cyp A, all of which are involved in nuclear transport machineries (Bieniasz 2012; Matreyek et al. 2013b). Because CA does not possess its own NLS, it may provide anchoring sites or pockets for PIC proteins, allowing transport of PIC into the nucleus. In addition, study of the chimeric HIV-1/MLV viruses and some CA mutants highlight the role of CA in nuclear import. Replacement of HIV-1 CA and MA with the same proteins from MLV decreases HIV-1 infectivity through accumulation of 2-LTR in non-dividing cells (Yamashita and Emerman 2004). Several HIV-1 CA mutants and MLV CA generate larger PICs than WT HIV-1, thereby slowing disassembly and disabling transport of the PIC through the NPC

(Dismuke and Aiken 2006; Fassati 2006; Matreyek and Engelman 2013a). Therefore, CA may 
407 change the accessibility of PIC to the host or viral proteins that determine nuclear entry, 408 ultimately determining the fate of nuclear import in non-dividing cells.

409 Recently yeast two-hybrid screening identified putative CA binding proteins (MAP1A, MAP1S, 410 CKAP1, and WIRE), which are known cytoskeletal components. Depletion of MAP1A/MAP1S 411 leads to lower viral infectivity because of defective nuclear entry (Fernandez et al. 2015). HIV-1

412 CA interacts with human MAP1A and MAP1S, which are microtubule-associated proteins that 413 presumably mediate tethering of HIV-1 CA to cytoskeletons. Otherwise, a large amount of 414 capsids accumulate throughout the cytoplasm (Fernandez et al. 2015).

415 Most recently, the crystal structure of the novel HIV-1 inhibitor BI-2 revealed that, similar to the 416 small molecule inhibitor PF74, BI-2 also binds in the site 2 pocket of the N-terminus of CA. 417 Although BI-2 is required at higher concentrations (about 10-fold) than PF74 to inhibit HIV-1 418 infection, it is not toxic to host cells (Fricke et al. 2014). PF74 prevents the binding of CPSF6 to 419 the same pocket in CA, thus destabilizing the HIV-1 core (Fricke et al. 2013, 2014). 420 Additionally, a novel assay for measuring HIV-1 CA-NC complex stability showed that the 421 cytosolic extracts, especially CPSF6, can stabilize the CA-NC complex like the drugs PF74 and 422 BI-2, while the peptide inhibitor CAI, an inhibitor of HIV-1 assembly in vitro (Sticht et al. 2005), is 423 similar to CypA in its ability to destabilize the comlex (Fig. 3). Interestingly, PF74 decreases 424 both 1-LTR and 2-LRT formation, whereas BI-2 interferes with 2-LTR formation but has no 425 effect on late reverse transcription. These data suggest that PF74 functions during the reverse 426 transcription step, while BI-2 works after reverse transcription but prior to nuclear entry (Fricke 427 et al. 2014) (Fig. 3). 
428

429

430

431

432

433

434

435

436

437

438

439

440

441

442

443

444

445

446

447

448

449

450

There are two NLSs in HIV-1 MA: NLS-1 (25GKKKYKLKH33) and NLS-2 (110KSKKK)

(Fouchier et al. 1997; Reil et al. 1998). MA mediates nuclear import through interaction with karyopherin $\alpha$. Truncated or full deletion mutants, and even those with point mutations at different positions $(9,26,27,67,72$, or 77$)$, display moderate interference with viral infection in both dividing and non-dividing cells, indicating that MA is dispensable in nuclear entry (Bukrinsky 2004; Kaushik and Ratner 2004; Fassati 2006). Interestingly, phosphorylation of Tyr-132 and Ser-111 in MA by the ERK family member ERK2 is critical for HIV-1 infection (Suzuki and Craigie 2007) and nuclear localization of the PIC, which was confirmed through the use of Ser-Thr phosphatase inhibitors (Kaushik and Ratner 2004, Giroud et al. 2011). Rather, MA is involved in Crm1-dependent nuclear export due to the presence of an NES (Baluyot et al. 2012). The coexistence of an NLS and NES in MA is puzzling, raising questions about its major function. Comparison to other cellular proteins with the same properties, such as STAT1 and ERK5, provided the theoretical insight that the putative NLSs of MA may undergo unknown biophysical or biochemical modification upon phosphorylation and display a conditional NES, which uses CRM1 as a carrier protein. MA phosphorylation likely unmasks or activates the NLS, stimulating the directional movement of the PIC to the nucleus (Nardozzi et al. 2010). This is likely only one of several factors relevant to this import process.

Integrase. HIV-1 IN, a $32 \mathrm{kDa}$ protein processed from Pol polyprotein, is composed of three functional domains: the N-terminal domain (NTD)/Zn-binding motif (residues 1-50), the central core domain (CCD) (residues 51-212), and the C-terminal domain (CTD)/DNA-binding motif (residues 213-288). IN integrates viral cDNA into the host genome with the help of diverse cellular proteins. Cellular factors such as TNPO3 (Larue et al. 2012), barrier-to-autointegration factor (Lin and Engelman 2003), LEDGF/p75 (Cherepanov et al. 2003), high-mobility group 
451 protein (HMG I(Y)) (Llano et al. 2004b), IN interactor protein-1 (Yung et al. 2001), DNA452 dependent protein kinase (Daniel et al. 1999), and DNA repair protein hRad18 (Mulder et al. 453 2002) all bind IN (Llano et al. 2004b). Lentiviral HIV-1 and FIV INs depend on LEDGF for 454 nuclear localization and protection from ubiquitin-proteasome, while the IN of the oncoretrovirus 455 MoMLV does not, although all of them can be co-immunoprecipitated with LEDGF (Llano et al. 456 2004a). Although HIV-1 IN contains a basic bipartite-type NLS at residues 186-188 and 211-219 457 and an atypical NLS in the CCD at 161-173 (Tsurutani et al. 2000; Bouyac-Bertoia et al. 2001; 458 Ao et al. 2004), its dispensable role in nuclear trafficking might be attributed (Petit el al. 2000). 459 Similarly, NLS-properties were also found in the arginine-and lysine-rich C-terminus of foamy 460 virus IN (Hossain et al. 2014). Nuclear localization of over-expressed full-length IN and 461 disability in 2-LTR production by IN-CTD deletion mutants provide strong evidence of its 462 karyophilic role. Recent studies show that the IN CTD interacts with both importin $\alpha 3$ and 463 importin 7, as well as with TNPO3, for passage through the NPC (Levin et al. 2010a). The IN 464 CTD-importin 7 interaction mediated import is specific for digitonin-permeabilized cell systems. 465 A reduction in HIV-1 infectivity was observed in HeLa and glioma cells (Fassati et al. 2003; 466 Bukrinsky 2004; Ao et al. 2004). While slipping through the NPC, IN can also bind with Nup153 467 (Woodward et al. 2009) and Nup62 (Ao et al. 2012). Although KD of Nup153 interferes with 468 nuclear translocation of viral cDNA, Nup62 KD impairs only cDNA integration and not reverse 469 transcription or the nuclear import step (Ao et al. 2012). The molecular mechanism of such 470 biased behavior is not yet understood.

471 Rev. Regulator of expression of the virion (Rev), one of the HIV-1 regulatory proteins, harbors

472 both an NLS and NES and contributes to the export of Rev responsive element (RRE)-containing 473 spliced or unspliced mRNA (Cullen 2003; Strebel 2003; Zhang et al. 2010). Interestingly, Rev 
474 can bind with IN and, as proposed in a recent model, might balance the movement of IN between

475 the cytoplasm and nucleus (Levin et al. 2010b). Over-expression of Rev or Rev-IN complexes

476 inhibits nuclear translocation of IN, while deletion mutants of Rev hamper nuclear import of IN

477 (Levin et al. 2010b), thereby suggesting the direct involvement of Rev in IN movement.

478 Additionally, Rev relies on NUP BP2 for its own nuclear entry (Zhang et al. 2010).

479 Vpr. Viral protein R, or Vpr, has many functions: it regulates apoptosis, arrests the cell cycle at 480 the G2 stage by binding to DDB1 and Cul4-associated factor 1 (DCAF1), and RNA splicing 481 (Nitahara-Kasahara et al. 2007; Kogan and Rappaport 2011). Despite the absence of a functional 482 NLS, it exhibits karyophilic properties during PIC nuclear transport. Primarily, it interacts with 483 three forms of importin $\alpha(\alpha 1, \alpha 3, \alpha 5)$ and with nuclear pore proteins in non-dividing cells in an 484 importin $\beta$-independent manner. Vpr is insensitive to high concentrations of ATP or lower NTP 485 levels, suggesting its energy-independent movement. NMR studies reveal that it is comprised of 486 three helices, $\alpha-\mathrm{H} 1$ (13-33), $\alpha-\mathrm{H} 2$ (38-50), and $\alpha-\mathrm{H} 3$ (55-77), which have different functions. 487 However, another range of residues, 17-34 and 46-74, shows independent nuclear localization, 488 which can be blocked by any mutation among these regions (Kamata and Aida 2000). Vpr 489 oligomerization determines the sub-cellular localization of Vpr but not its pro-apoptotic activity 490 (Fritz et al. 2008). Vpr requires interaction with the C-terminus of p55 Gag polyprotein precursor 491 (Pr55gag) to anchor with assembling virion particles (Bachand et al. 1999). However, the PIC is 492 ubiquitously found to be associated with proteins of the microtubular network, such as actin and 493 dynein, during cytoplasmic migration. A Vpr-GFP fusion construct was used to track the role of 494 Vpr in PIC movement in living cells, revealing movement throughout the cytoplasm along 495 cytoskeletal filaments and accumulation in the perinuclear region (McDonald et al. 2002). 496 Although $\mathrm{Vpr}$ is an integral component of the PIC, it is unclear whether Vpr assists in PIC 
497

498

499

500

501

502

503

504

505

506

507

508

509

510

511

512

513

514

515

516

517

518

519

movement. Vpr can associate with Nup153 (Woodward et al. 2009), Pom121 (Matreyek and Engelman 2013a), and human nucleoporin CG1 (Le Rouzic et al. 2002; Matreyek and Engelman $2013 a$ ) both in vitro and in transfected cells. Using a photobleaching experiment in living cells, the nucleocytoplasmic shuttling of $\mathrm{Vpr}$, which prominently occurs in the nuclear envelope, was confirmed (Le Rouzic et al. 2002). Therefore, this protein may influence cleavage of the nuclear envelope, facilitating the travel of PICs through the NPC, which might explain how Vpr induces apoptosis.

Central DNA flap. During reverse transcription, binding of tRNA to the primer binding site (PBS) initiates formation of the minus-strand strong-stop DNA and subsequent elongation. The central DNA flap is generated as a result of $(+)$ strand initiation at the central polypurine tract (cPPT) and termination after about $100 \mathrm{bp}$ strand displacement at the central termination sequence (CTS) (Iglesias et al. 2011). In lentiviruses, positive-strand strong-stop DNA initiation at two distinct sites leads to displacement of the downstream strand containing about 99 nucleotides of overlap until the CTS is reached. This generates a single-stranded overlapping DNA fragment called the central DNA flap, which acts as a cis-determinant of HIV-1 DNA nuclear import (Sirven et al. 2000). Although the genome of the reverse transcription complex (RTC) can consist of either RNA or RNA-DNA intermediates, PIC does not contain RNA species (Suzuki and Craigie 2007). Instead, along with viral karyophilic proteins and several cellular proteins, the overlapped portion of viral cDNA causes the nuclear import of PIC and integration into cellular DNA. When a sequence of the DNA flap is introduced in an HIVderived vector in human CD34+ hematopoietic stem cells, there is increase in gene transduction ability (Sirven et al. 2000). Mutations in either the HIV-1 cPPT or C-terminal sequence can impair viral replication in MT4 cells, CEM cells, and PBMCs (Zennou et al. 2000; De Rijck et 
520

521

522

523

524

525

526

527

528

529

530

531

532

533

534

535

536

537

538 Conclusions and future perspectives

539 More than 30 years after the discovery of HIV-1, researchers have achieved significant successes 540 541 treatment leading to cure. AIDS drug design and selection are limited due to side effects 542

al. 2005). Insufficient ability of flap negative HIV-1 to infect HeLa cells could be due to delayed 2-LTR formation. However, the role of the flap in nuclear import is contested (Limón et al. 2002; Dvorin et al. 2002). The observation that HIV-1 replication in a single-cycle replication system is defective but increases 5-7 fold in dividing and non-dividing cell lines indicates its specificity for strain and host cell types (Follenzi et al. 2000). Fluorescence in situ hybridization (FISH) analysis of the sub-cellular distribution of viral cDNA between wild type and DNA flapdefective mutant demonstrated that wild-type DNA including the DNA Flap accumulates predominantly inside the nucleus of transduced cells $48 \mathrm{hr}$ post-transduction, and more specifically within open regions of the chromatin. However DNA flap defective viral genomes accumulate on the cytoplasmic side of the nuclear membrane (Arhel et al. 2006). Flap may have a protective role in viral cDNA stability, based on the observation that PIC collected at 10 hours, but not that from earlier samples, is resistant to DNase I digestion (Ao et al. 2004). However, both cPPT and CTS are essential for a functional central DNA flap, as viral infectivity and gene transfer are impaired in mutants. Most disrupted DNA flap mutants can maintain residual nuclear import, which accounts for 5-15\% of the WT HIV-1 (Iglesias et al. 2011). Although the entry of residual amounts of PIC in the absence of the central DNA flap occurs with very low efficiency, reinsertion of cPPT or CTS sequences recovers the viral infectivity and gene transfer efficacy by increasing nuclear import (Follenzi et al. 2000; Zennou et al. 2000; Iglesias et al. 2011).

in the control and treatment of HIV-1 viremia but are still a long way from finding a suitable occurring because of utilization of cellular proteins by viral proteins. Interestingly, viral particle 
543 and host protein interactions have been targeted for new therapeutic targets over the last two 544 decades. This review summarizes the progress in the understanding of nuclear import from both 545 cellular and viral aspects.

The nucleus is a selective permeable compartment and prevents free diffusion of random

547 proteins. Retroviruses have evolved numerous mechanisms to evade the tight cellular regulatory 548 systems, even circumventing several host proteins, to reach the nucleus.

549 Nuclear import is a critical step in the retroviral life cycle and consists of flexible utilization of 550 cellular cofactors to access the nucleus (Lee et al. 2010). The viral capsid determines the 551 requirement of TNPO3 during HIV-1 infection. Full length CPSF6 binds to the HIV-1 capsid by 552 interacting with a distinct conserved interface, which dictates the dependence on TNPO3 and 553 Nup358. Moreover, when CPSF6 is confined to the cytoplasm, the stability of the incoming viral 554 core increases, similar to CypA (Li et al., 2009; De Iaco et al., 2013; Fricke et al., 2013; Shah et 555 al., 2013). Current research indicates an orchestrated protein-protein network is required for 556 retroviral nuclear transport. Since different cell lines have distinctive cell signaling pathways and 557 cellular status, these parameters may influence the nuclear import of retroviral PICs (Levin et al. 558 2011).

559 The current research on HIV-1-related nucleocytoplasmic transport has been confined to nuclear 560 localization signal (NLS)-containing proteins and their carriers (Stewart 2007). The search for 561 NLS-independent pathways and more careful study of the unveiled NLS-exhibiting sequences in 562 viral proteins are important areas for future research. Additionally, the simultaneous and flexible 563 use of cellular cofactors by HIV-1 proteins is another important research topic. Research 564 regarding debated results and models needs to be carried out as it is important that we do not 
565 neglect controversial results. Some of these contested issues may be due to use of different cell

566 lines (e.g., immature/adult, native/specialized cell lines) under different conditions (temperature,

567 reagents, incubation time), or simply due to handling. Although there are some debated topics,

568 the viral proteins for egress are known and agreed upon, such as importin $\beta$ (Henderson and 569 Percipalle 1997), NUP98 (Zolotukhin and Felber 1999), NUP214 (Zolotukhin and Felber 1999;

570 Hutten and Kehlenbach 2006), and Hsp70 (Multhoff 2007). In this review, we compiled the data

571 available in current literature on host-pathogen interaction in HIV-1 nuclear transport. This

572 review will be helpful in determining new therapeutic targets.

573

574

575

\section{Acknowledgements}

577 This study was supported by a grant from the National Research Foundation of Korea (NRF),

578 funded by the Korean government (2011-0011256).

579

\section{Competing interests}

581 The authors declare that they have no competing interests.

\section{References}


585 586

587

588

589

590

591

592

593

594

595

596

597

598

599

600

601

602

603

604

605

606

607

Agostini, I., Popov, S., Li, J., Dubrovsky, L., Hao, T., and Bukrinsky, M. 2000. Heat-shock protein70 can replace viral protein $\mathrm{R}$ of HIV-1 during nuclear import of the viral preintegration complex. Exp. Cell. Res. 259(2): 398-403. doi:10.1006/excr.2000.4992. PMID:10964507

Ali, M.K., Kim, J., Hamid, F.B., and Shin C.G. 2015. Knockdown of the host cellular protein transportin 3 attenuates prototype foamy virus infection. Biosci. Biotechnol. Biochem. 9: 1-9. doi:10.1080/09168451.2015.1008973. PMID:25660973.

Ao, Z., Huang, G., Yao, H., Xu, Z., Labine, M., Cochrane, A.W., and Yao, X. 2007. Interaction of human immunodeficiency virus type 1 integrase with cellular nuclear import receptor importin 7 and its impact on viral replication. J. Biol. Chem. 282(18): 6-67. doi:10.1074/jbc.M610546200. PMID:17360709

Ao, Z., DanappaJayappa, K., Wang B., Zheng, Y., Kung, S., Rassart, E., Depping, R., Kohler, M., Cohen, E.A., and Yao, X. 2010. Importin $\alpha 3$ interacts with HIV-1 integrase and contributes to HIV-1 nuclear import and replication. J.Virol. 84(17): 8650-63. doi:10.1128/JVI.00508-10. PMID:20554775.

Ao, Z., Jayappa, K.D., Wang, B., Zheng, Y., Wang, X., Peng, J., and Yao, X. 2012. Contribution of host nucleoporin 62 in HIV-1 integrase chromatin association and viral DNA integration. J. Biol. Chem. 287(13): 10544-55. PMID:22308026.

Ao, Z., Yao, X., and Cohen, E.A. 2004. Assessment of the role of the central DNA flap in human immunodeficiency virus type 1 replication by using a single-cycle replication system. J. Virol. 78(6):3170-7. doi:10.1128/JVI.78.6.3170-3177.2004. PMID:14990738.

Arhel, N. 2010. Revisiting HIV-1 uncoating. Retrovirology, 7: 96. doi:10.1186/1742-4690-7-96. PMID:21083892. 
608 609

610

611

612

613

614

615

616

617

618

619

620

621

622

623

624

625

626

627

628

629

Arhel, N.J., Souquere-Besse, S., Charneau, P. 2006. Wild-type and central DNA flap defective HIV-1 lentiviral vector genomes, intracellular visualization at ultrastructural resolution levels. Retrovirology, 3: 38. doi: 10.1186/1742-4690-3-38. PMID: 16800894.

Arnold, M., Nath A., Hauber, J., and Kehlenbach, R.H. 2006. Multiple importins function as nuclear transport receptors for the Rev protein of human immunodeficiency virus type 1. J. Biol. Chem. 281(30): 20883-90. doi:10.1074/jbc.M602189200. PMID:16704975.

Bachand, F., Yao, X.J., Hrimech, M., and Rougeau, N., Cohen, E.A. 1999. Incorporation of Vpr into human immunodeficiency virus type 1 requires a direct interaction with the p6 domain of the p55 gag precursor. J Biol Chem. 274(13): 9083-91. PMID:10085158.

Ball, J. R., and Ullman, K. S. 2005. Versatility at the nuclear pore complex, lessons learned from thenucleoporin Nup153. Chromosoma, 114(5): 319-330. PMID:16133350.

Baluyot, M.F., Grosse, S.A., Lyddon, T.D., Janaka, S.K., and Johnson, M.C. 2012. CRM1dependent trafficking of retroviral Gag proteins revisited. J.Virol. 86(8): 4696-700. doi:10.1128/JVI.07199-11. PMID:22318151.

Bieniasz P.D. 2012. An overview of intracellular interactions between immunodeficiency viruses and their hosts. AIDS. 26(10): 1243-54. doi:10.1097/QAD.0b013e328353bd04. PMID:22472854.

Biswas, N., Wang, T., Ding, M., Tumne, A., Chen, Y., Wang, Q, and Gupta, P. 2012. ADAR1 is a novel multi targeted anti-HIV-1 cellular protein. Virology. 422(2):265-77. doi: 10.1016/j.virol.2011.10.024. PMID:22104209.

Borner, K., Hermle, J., Sommer, C., Brown, N.P., Knapp, B., Glass, B., Kunkel, J., Torralba, G., Reymann, J., Beil, N., Beneke, J., Pepperkok, R., Schneider, R., Ludwig, T., Hausmann, 
630

631

632

633

634

635

636

637

638

639

640

641

642

643

644

645

646

647

648

649

650

M., Hamprecht, F., Erfle, H., Kaderali, L., Krausslich, H.G., and Lehmann, M.J. 2010.

From experimental setup to bioinformatics, an RNAi screening platform to identify host factors involved in HIV-1 replication. Biotechnol. J. 5(1):39-49. doi:10.1002/biot.200900226. PMID:20013946.

Bouyac-Bertoia, M., Dvorin, J.D., Fouchier, R.A., Jenkins, Y., Meyer, B.E., Wu, L.I., Emerman, M., and Malim, M.H. 2001. HIV-1 infection requires a functional integrase NLS. Mol. Cell, 7(5):1025-1035. doi:10.1016/S1097-2765(01)00240-4. PMID:11389849.

Brass, A.L., Dykxhoorn, D.M., Benita, Y., Yan, N., Engelman, A., Xavier, R.J., Lieberman, J., and Elledge, S.J. 2008. Identification of host proteins required for HIV infection through a functional genomic screen. Science, 319(5865): 921-6. doi:10.1126/science.1152725. PMID:18187620.

Bukong, T.N., Hall, W.W., and Jacqué, J.M. 2010. Lentivirus-associated MAPK/ERK2 phosphorylates EMD and regulates infectivity. J. Gen.Virol. 91(9): 2381-92. PMID:20463147.

Bukrinsky, M. 2004. A hard way to the nucleus. Mol. Med. 10(1-6): 1-5. doi:10.1099/vir.0.019604-0. PMID:15502876.

Bushman, F.D., Malani, N., Fernandes, J., D’Orso, I., Cagney, G., Diamond, T.L., Zhou, H., Hazuda, D.J., Espeseth, A.S., Konig, R., Bandyopadhyay, S., Ideker, T., Goff, S.P., Krogan, N.J., Frankel, A.D., Young, J.A., and Chanda, S.K. 2009. Host cell factors in HIV replication:meta-analysis of genome-wide studies. PLoS Pathog. 5: e1000437. doi:10.1371/journal.ppat.1000437. PMID:19478882. 
651 Campbell, E.M., and Hope, T.J. 2015. HIV-1 capsid: the multifaceted key player in HIV-

652

653

654

655

656

657

658

659

660

661

662

663

664

665

666

667

668

669

670

671

672

1 infection. Nat Rev Microbiol. 13(8):471-83. doi: 10.1038/nrmicro3503. PMID:26179359.

Cardarelli, F., Lanzano, L., and Gratton, E. 2012. Capturing directed molecular motion in the nuclear pore complex of live cells. Proc. Natl. Acad. Sci. U.S.A. 109(25): 9863-8. doi:10.1073/pnas.1200486109. PMID:22665783.

Cardinale, S., Cisterna, B., Bonetti, P., Aringhieri, C., Biggiogera, M., and Barabino, S.M. 2007. Subnuclear localization and dynamics of the Pre-mRNA $3^{\prime}$ end processing factor mammalian cleavage factor I 68-kDa subunit. Mol Biol Cell. 18(4):1282-92. PMID:17267687.

Cartier, C., Deckert, M., Grangeasse, C., Trauger, R., Jensen, F., Bernard, A., Cozzone, A., Desgranges, C., and Boyer, V. 1997. Association of ERK2 mitogen-activated protein kinase with human immunodeficiency virus particles. J.Virol. 71(6): 4832-4837. PMID:9151881.

Chan, E.Y., Qian, W.J., Diamond, D.L., Liu, T., Gritsenko, M.A., Monroe, M.E., Camp, D.G., Smith, R.D., and Katze, M.G. 2007. Quantitative analysis of human immunodeficiency virus type 1-infected $\mathrm{CD} 4+$ cell proteome, dysregulated cell cycle progression and nuclear transport coincide with robust virus production. J. Virol. 81(14): 7571-7583. doi:10.1128/JVI.00288-07. PMID:17494070.

Chan, E., Towers, G.J., and Qasim, W. 2014. Gene therapy strategies to exploit TRIM derived restriction factors against HIV-1. Viruses. 6(1):243-263. doi:10.3390/v6010243. PMID:24424502. 
673 Cherepanov, P., Maertens, G., Proost, P., Devreese, B., Van Beeumen, J., Engelborghs, Y., De 674 Clercq, E., and Debyser, Z. 2003. HIV-1 integrase forms stable tetramers and associates 675 676

677 678 679 680 681 682 683 684 685 686 687 688 689 690 691 692 693 694 695 with LEDGF/p75 protein in human cells. J. Biol. Chem. 278(1): 372-81. doi:10.1074/jbc.M209278200. PMID:12407101.

Christ, F., Thys W., De Rijck, J., Gijsbers, R., Albanese, A., Arosio, D., Emiliani, S., Rain, J.C., Benarous, R., Cereseto, A., and Debyser, Z. 2008. Transportin-SR2 imports HIV into the nucleus. Curr. Biol. 18(16): 1192-202. doi:10.1016/j.cub.2008.07.079. PMID:18722123.

Cingolani, G., Bednenko, J., Gillespie, M.T., and Gerace, L. 2002. Molecular basis for the recognition of a nonclassical nuclear localization signal by importin beta. Mol. Cell 10(6): 1345-53. doi:10.1016/S1097-2765(02)00727-X. PMID:12504010.

Coffin, J.M., Hughes, S.H., and Varmus, H. E. 1997. Retroviruses. Cold Spring Harbor Laboratory Press, Plainview, New York.

Cohen, S., Au, S., and Panté, N. 2011. How viruses access the nucleus. Biochim Biophys Acta. 1813(9):1634-45. doi: 10.1016/j.bbamcr.2010.12.009. PMID:21167871.

Copeland, A.M., Newcomb, W.W., and Brown, J.C. 2009. Herpes simplex virus replication, roles of viral proteins and nucleoporins in capsid-nucleus attachment. J. Virol. 83(4):1660-8. doi:10.1128/JVI.01139-08. PMID:19073727.

Cribier, A., Ségéral, E., Delelis, O., Parissi, V., Simon, A., Ruff, M., Benarous, R., and Emiliani, S. 2011. Mutations affecting interaction of integrase with TNPO3 do not prevent HIV-1 cDNA nuclear import. Retrovirology, 8: 104. doi:10.1186/1742-4690-8-104. PMID:22176773.

Cullen, B.R. 2003. Nuclear mRNA export, insights from virology. Trends Biochem. Sci. 28(8): 419-424. doi:10.1016/S0968-0004(03)00142-7. PMID:12932730. 
696 Cullen, B.R. 2006. Role and mechanism of action of the APOBEC3 family of antiretroviral

697

698

699

700

701

702

703

704

705

706

707

708

709

710

711

712

713

714

715

716

717 resistance factors. J. Virol. 80 (3): 1067-76. doi:10.1128/JVI.80.3.1067-1076.2006. PMID 16414984.

Daniel, R., Katz, R.A., and Skalka, A.M. 1999. A role for DNA-PK in retroviral DNA integration. Science, 284(5414):644-7. doi:10.1126/science.284.5414.644. PMID:10213687.

Daugaard, M., Rohde, M., and Jäättelä, M. 2007. The heat shock protein 70 family, Highly homologous proteins with overlapping and distinct functions. FEBS Lett. 581(19): 370210. doi:10.1016/j.febslet.2007.05.039. PMID:17544402.

De Houwer,S., Demeulemeester, J., Thys, W., Rocha, S., Dirix, L., Gijsbers, R., Christ, F., and Debyser, Z. 2014. The HIV-1 integrase mutant R263A/K264A is 2-fold defective for TRN-SR2 binding and viral nuclear import. J. Biol. Chem. 289(36): 25351-61. doi:10.1074/jbc.M113.533281. PMID:25063804.

De Iaco, A., and Luban, J. 2011. Inhibition of HIV-1 infection by TNPO3 depletion is determined by capsid and detectable after viral cDNA enters the nucleus. Retrovirology, 8:98. doi:10.1186/1742-4690-8-98. PMID:22145813.

De Iaco, A., Santoni, F., Vannier, A., Guipponi, M., Antonarakis, S., and Luban, J. 2013. TNPO3 protects HIV-1 replication from CPSF6-mediated capsid stabilization in the host cell cytoplasm. Retrovirology, 10: 20. doi:10.1186/1742-4690-10-20. PMID:23414560.

Delelis, O., Saib, A., and Sonigo, P. 2003. Biphasic DNA synthesis in spumaviruses. J Virol. 77(14): 8141-8146. doi:10.1128/JVI.77.14.8141-8146.2003. PMID:12829852.

Delelis, O., Petit, C., Leh, H., Mbemba, G., Mouscadet, J.F., and Sonigo, P. 2005. A novel function for spumaretrovirus integrase: an early requirement for integrase-mediated 
718

719

720

721

722

723

724

725

726

727

728

729

730

731

732

733

734

735

736

737

738

739

cleavage of 2 LTR circles.Retrovirology, 2: 31. doi:10.1186/1742-4690-2-31. PMID:15904533.

De Rijck, J., Van Maele, B., and Debyser, Z. 2005. Positional effects of the central DNA flap in HIV-1-derived lentiviral vectors. Biochem. Biophys. Res. Commun. 328(4): 987-94. doi:10.1016/j.bbrc.2005.01.052. PMID:15707975.

Di Nunzio, F., Danckaert, A., Fricke, T., Perez, P., Fernandez, J., Perret, E., Roux, P., Shorte, S., Charneau, P., Diaz-Griffero, F., and Arhel, N.J. 2012. Human nucleoporins promote HIV-

1 docking at the nuclear pore, nuclear import and integration. PLoS One, 7(9): e46037. doi:10.1371/journal.pone.0046037. PMID:23049930.

Di Nunzio, F., Fricke, T., Miccio, A., Valle-Casuso, J.C., Perez, P., Souque, P., Rizzi, E., Severgnini, M., Mavilio, F., Charneau, P., and Diaz-Griffero, F. 2013. Nup153 and Nup98 bind the HIV-1 core and contribute to the early steps of HIV-1 replication. Virology, 440(1):8-18. doi:10.1016/j.virol.2013.02.008. PMID:23523133

Dismuke, D.J., and Aiken, C. 2006. Evidence for a functional link between uncoating of the human immunodeficiency virus type 1 core and nuclear import of the viral preintegration complex. J. Virol. $\quad \mathbf{8 0}(8): \quad 3712-3720 . \quad$ doi:10.1128/JVI.80.8.3712-3720.2006. PMID:16571788.

Dvorin, J.D., Bell, P., Maul, G.G., Yamashita, M., Emerman, M., and Malim, M.H. 2002. Reassessment of the roles of integrase and the central DNA flap in human immunodeficiency virus type 1 nuclear import. J. Virol. 76(23): 12087-96. doi:10.1128/JVI.76.23.12087-12096.2002. PMID:12414950. 
740

741

742

743

744

745

746

747

748

749

750

751

752

753

754

755

756

757

758

759

760

761

762

Ebina, H., Aoki, J., Hatta, S., Yoshida, T., and Koyanagi, Y. 2004. Role of Nup98 in nuclear entry of human immunodeficiency virus type 1 cDNA. Microbes Infect. 6(8): 715-724. doi:10.1016/j.micinf.2004.04.002. PMID:15207818.

Fassati, A. 2006. HIV infection of non-dividing cells, a divisive problem. Retrovirology. 3, 74. doi:10.1186/1742-4690-3-74. PMID:17067381.

Fassati, A., Görlich, D., Harrison, I., Zaytseva, L., and Mingot, J.M. 2003. Nuclear import of HIV-1 intracellular reverse transcription complexes is mediated by importin 7. EMBO J. 22(14): $\quad$ 3675-85. doi:10.1093/emboj/cdg357. PMID:12853482.

Fernandez, J., Portilho, D.M., Danckaert, A., Munier, S., Becker, A., Roux, P., Zambo, A., Shorte, S., Jacob, Y., Vidalain, P.O., Charneau, P., Clavel, F., and Arhel, N.J. 2015. Microtubule-associated proteins 1 (MAP1) promote human immunodeficiency virus type I (HIV-1) intracytoplasmic routing to the nucleus. J Biol Chem. 290(8):4631-46. doi: 10.1074/jbc.M114.613133. PMID:25505242.

Follenzi, A., Ailles, L.E., Bakovi,c S., Geuna, M., and Naldini, L. 2000. Gene transfer by lentiviral vectors is limited by nuclear translocation and rescued by HIV-1 pol sequences. Nat. Genet. 25(2): 217-22. doi:10.1038/76095. PMID:10835641.

Fouchier, R.A., Meyer, B.E., Simon, J.H., Fischer, U., and Malim, M.H. 1997. HIV-1 infection of non-dividing cells, evidence that the amino-terminal basic region of the viral matrix protein is important for Gag processing but not for post-entry nuclear import. EMBO J. 16(15): 4531-9. doi:10.1093/emboj/16.15.4531. PMID:9303297.

Fricke, T., Brandariz-Nunez, A., Wang, X., Smith, A.B., and Diaz-Griffero, F. 2013. Human cytosolic extracts stabilize the HIV-1 core. J.Virol. 87(19): 10587-97. doi:10.1128/JVI.01705-13. PMID:23885082. 
763 Fricke, T., Buffone, C., Opp, S., Valle-Casuso, J., and Diaz-Griffero, F. 2014. BI-2 destabilizes 764 HIV-1 cores during infection and Prevents Binding of CPSF6 to the HIV-1 Capsid. Retrovirology, 11(1):120. doi:10.1186/s12977-014-0120-x. PMID:25496772.

766

767

768

769

770

771

772

773

774

775

776

777

778

779

780

781

782

783

784

785

Bouaziz, S., Darlix, J.L., Mély, Y., and de Rocquigny, H. 2008. Direct Vpr-Vpr

interaction in cells monitored by two photon fluorescence correlation spectroscopy and fluorescence lifetime imaging. Retrovirology, 5: 87. doi:10.1186/1742-4690-5-87.

PMID:18808682.

Giroud, C., Chazal, N., and Briant, L. 2011. Cellular kinases incorporated into HIV-1 particles, passive or active passengers? Retrovirology, 8: 71. doi:10.1186/1742-4690-8-71. PMID:21888651.

Goff, S. P. 2007. Host factors exploited by retroviruses. Nat. Rev. Microbiol. 5: 253-63. doi:10.1038/nrmicro1541. PMID:17325726.

Gruber, A.R., Martin, G., Keller, W., and Zavolan, M. 2012. Cleavage factor Im is a key regulator of 3' UTR length. RNA Biol. 9: 1405-12. doi:10.4161/rna.22570. PMID:23187700.

Gustin, K.E., and Sarnow. P. 2001. Effects of poliovirus infection on nucleocytoplasmic trafficking and nuclear pore complex composition. EMBO J. 20(1-2): 240-249. doi:10.1093/emboj/20.1.240. PMID:11226174.

Henderson, B.R., and Percipalle, P. 1997. Interactions between HIV Rev and nuclear import and export factors, the Rev nuclear localization signal mediates specific binding to human importin-beta. J. Mol. Biol. 274(5): 693-707. doi:10.1006/jmbi.1997.1420. PMID:9405152. 
786

787

788

789

790

791

792

793

794

795

796

797

798

799

800

801

802

803

804

805

806

807

Hombrouck, A., De Rijck, J., Hendrix, J., Vandekerckhove, L., Voet, A., De Maeyer, M., Witvrouw, M., Engelborghs, Y., Christ, F., Gijsbers, R., and Debyser, Z. 2007. Virus evolution reveals an exclusive role for LEDGF/p75 in chromosomal tethering of HIV. PLoS Pathog. 3(3): e47. doi:10.1371/journal.ppat.0030047. PMID:17397262.

Hombrouck, A., Van Remoortel, B., Michiels, M., Noppe, W., Christ, F., Eneroth, A., Sahlberg, B.L., Benkestock, K., Vrang, L., Johansson, N.G., Barreca, M.L., De Luca, L., Ferro, S., Chimirri, A., Debyse,r Z., and Witvrouw, M. 2008. Preclinical evaluation of

$1 \mathrm{H}-$ benzylindolederivatives as novel human immunodeficiency virus integrase strand transfer inhibitors. Antimicrob. Agents Chemother. 52(8): 2861-2869. doi: 10.1128/AAC.00210-08. PMID:18541726.

Hossain, A., Ali, K., and Shin, C.G. 2014. Nuclear localization signals in prototype foamy viral integrase for successive infection and replication in dividing cells. Mol. Cells, 37(2): 1408. doi:10.14348/molcells.2014.2331. PMID:24598999.

Huthoff, H., and Towers, G.J. 2008. Restriction of retroviral replication by APOBEC3G/F and TRIM5 $\alpha$. Trends microbial. 16(12):612-619. doi:10.1016/j.tim.2008.08.013. PMID:18976920.

Hutten, S., and Kehlenbach, R.H. 2006. Nup214 is required for CRM1-dependent nuclear protein export in vivo. Mol. Cell. Biol. 26(18): 6772-85. doi:10.1128/MCB.00342-06. PMID:16943420.

Hutten, S., Wälde, S., Spillner, C., Hauber, J., and Kehlenbach, R.H. 2009. The nuclear pore component Nup358 promotes transportin-dependent nuclear import. J. Cell. Sci. 122(Pt 8): 1100-10. doi:10.1242/jcs.040154. PMID:19299463. 
808 Iglesias, C., Ringeard, M., Di Nunzio, F., Fernandez, J., Gaudin, R., Souque, P., Charneau, P., 809 and Arhel, N. 2011. Residual HIV-1 DNA Flap-independent nuclear import of cPPT/CTS double mutant viruses does not support spreading infection. Retrovirology, 8: 92. doi:10.1186/1742-4690-8-92. PMID:22074589.

812

Iwasaki, A., and Medzhitov, R. 2010.Regulation of adaptive immunity by the innate immune system. Science, 327(5963): 291-295. doi:10.1186/1742-4690-8-92. PMID:22074589.

Jacque, J.M., and Stevenson, M. 2006. The inner-nuclear-envelope protein emerin regulates

\section{6}

817

818

819

820

821

822

823

824

825

826

827

828

829 HIV-1 infectivity. Nature, 441(7093): 641-5. doi:10.1038/nature04682. PMID:16680152.

Kamata, M., and Aida, Y. 2000. Two putative alpha-helical domains of human immunodeficiency virus type $1 \mathrm{Vpr}$ mediate nuclear localization by at least two mechanisms. J. Virol. 74(15): 7179-7186. doi:10.1128/JVI.74.15.7179-7186.2000. PMID:10888660.

Kaushik, R., and Ratner, L. 2004. Role of human immunodeficiency virus type 1 matrix phosphorylation in an early postentry step of virus replication.J.Virol. 78(5):2319-26. doi:10.1128/JVI.78.5.2319-2326.2004. PMID:14963128.

Kogan, M., and Rappaport, J. 2011. HIV-1 Accessory Protein Vpr, Relevance in the pathogenesis of HIV and potential for therapeutic intervention. Retrovirology, 8: 25 . doi:10.1186/1742-4690-8-25. PMID:21489275.

König, R., Stertz, S., Zhou, Y., Inoue, A., Hoffmann, H.H., Bhattacharyya, S., Alamares, J.G., Tscherne, D.M., Ortigoza, M.B., Liang, Y., Gao, Q., Andrews, S.E., Bandyopadhyay, S., De Jesus, P., Tu, B.P., Pache, L., Shih, C., Orth, A., Bonamy, G., Miraglia, L., Ideker, T., García-Sastre, A., Young, J.A., Palese, P., Shaw, M.L., and Chanda, S.K. 2010. Human 
host factors required for influenza virus replication. Nature, 463(7282): 813-817. doi:10.1038/nature08699. PMID:20027183.

König, R., Zhou, Y., Elleder, D., Diamond, T.L., Bonamy, G.M., Irelan, J.T., Chiang, C.Y., Tu, B.P., De Jesus, P.D., Lilley, C.E., Seidel, S., Opaluch, A.M., Caldwell, J.S., Weitzman, M.D., Kuhen, K.L., Bandyopadhyay, S., Ideker, T., Orth, A.P., Miraglia, L.J., Bushman, F.D., Young, J.A., and Chanda, S.K. 2008. Global analysis of host-pathogen interactions that regulate early-stage HIV-1 replication. Cell, 135(1): 49-60. doi:10.1016/j.cell.2008.07.032. PMID:18854154.

Konstantoulas, C.J., and Indik, S. 2014. Mouse mammary tumor virus-based vector transduces non-dividing cells, enters the nucleus via a TNPO3-independent pathway and integrates in a less biased fashion than other retroviruses. Retrovirology, 11: 34. doi:10.1186/17424690-11-34. PMID:24779422.

Krishnan, L., Matreyek, K.A., Oztop, I., Lee, K., Tipper, C.H., Li, X., Dar, M.J., Kewalramani, V.N., and Engelman A. 2010. The requirement for cellular transportin 3 (TNPO3 or TRN- SR2) during infection maps to human immunodeficiency virus type 1 capsid andnot integrase. J.Virol. 84(1): 397-406. doi:10.1128/JVI.01899-09. PMID:19846519.

Lahaye, X., Satoh, T., Gentili, M., Cerboni, S., Conrad, C., Hurbain, I., El Marjou, A., Lacabaratz, C., Lelièvre, J.D., and Manel, N. 2013. The capsids of HIV-1 and HIV-2 determine immune detection of the viral cDNA by the innate sensor cGAS in dendritic cells. Immunity. 39(6):1132-42. doi: 10.1016/j.immuni.2013.11.002. PMID:24269171.

Lai, M.C., Lin, R.I., and Tarn, W.Y. 2001. Transportin-SR2 mediates nuclear import of phosphorylated SR proteins. Proc. Natl. Acad. Sci. U.S.A. 98(18): 101549.doi:10.1128/JVI.01899-09. PMID:19846519. 
853 Larue, R., Gupta, K., Wuensch, C., Shkriabai, N., Kessl, J.J., Danhart, E., Feng, L., Taltynov, O., 854 Christ, F., Van Duyne, G.D., Debyse,r Z., Foster, M.P., and Kvaratskhelia, M. 2012. Interaction of the HIV-1 intasome with transportin 3 protein (TNPO3 or TRN-SR2). J Biol Chem. 287(41): 34044-34058. doi:10.1074/jbc.M112.384669. PMID:22872640.

857

858

859

860

861

862

863

864

865

866

867

868

869

870

871

872

873

874

Le Rouzic, E., Mousnier, A., Rustum, C., Stutz, F., Hallberg, E., Dargemont, C., and Benichou, S. 2002. Docking of HIV-1 Vpr to the nuclear envelope is mediated by the interaction with the nucleoporin hCG1. J. Biol. Chem. 277(47):45091-8. doi:10.1074/jbc.M207439200. PMID:12228227.

Lee, K., Ambrose, Z., Martin, T.D., Oztop, I., Mulky, A., Julias, J.G., Vandegraaff, N., Baumann, J.G., Wang, R., Yuen, W., Takemura, T., Shelton, K., Taniuchi, I., Li, Y., Sodroski, J., Littman, D.R., Coffin, J.M., Hughes, S.H., Unutmaz, D., Engelman, A., and KewalRamani, V.N. 2010. Flexible use of nuclear import pathways by HIV-1. Cell Host Microbe, 7(3): 221-33. doi:10.1016/j.chom.2010.02.007. PMID:20227665.

Lee, K., Mulky, A., Yuen, W., Martin, T.D., Meyerson, N.R., Choi, L., Yu, H., Sawyer, S.L., and Kewalramani, V.N. 2012. HIV-1 Capsid targeting domain of cleavage and polyadenylation specificity factor 6. J.Virol. 86(7): 3851-60. doi:10.1128/JVI.06607-11. PMID:22301135.

Lee, M.S. and Craigie, R. 1998. A previously unidentified host protein protects retroviral DNA from autointegration. Proc. Natl. Acad. Sci. U.S.A. 95(4): 1528-1533. doi:10.1073/pnas.95.4.1528. PMID:9465049.

Lelek, M., Casartelli, N., Pellin, D., Rizzi, E., Souque, P., Severgnini, M., Di Serio, C., Fricke, T., Diaz-Griffero, F., Zimmer, C., Charneau, P., and Di Nunzio, F. 2015. Chromatin 
884

885

886

887

888

organization at the nuclear pore favours HIV replication. Nat Commun. 6:6483. doi: 10.1038/ncomms7483. PMID:25744187.

Levin, A., Hayouka, Z., Friedler, A., and Loyter, A. 2010a. Transportin 3 and importin $\alpha$ are required for effective nuclear import of HIV-1 integrase in virus-infected cells. Nucleus, 1(5): 422-31. doi:10.4161/nucl.1.5.12903. PMID:21326825.

Levin, A., Hayouka, Z., Friedler, A., and Loyter, A. 2010b. Nucleocytoplasmic shuttling of HIV1 integrase is controlled by the viral Rev protein. Nucleus, 1(2): 190-201. doi:10.4161/nucl.1.2.11300. PMID:21326951.

Levin, A., Loyter, A., and Bukrinsky, M. 2011. Strategies to inhibit viral protein nuclear import, HIV-1 as a target. Biochim. Biophys. Acta. 1813(1): 1646-53. doi:10.1016/j.bbamcr.2010.07.010. PMID:20719241.

Li, Y., Kar, A.K., and Sodroski, J. 2009. Target cell type-dependent modulation of human immunodeficiency virus type 1 capsid disassembly bycyclophilin A. J.Virol. 83(21): 10951- 62. doi:10.1128/JVI.00682-09. PMID:19656870.

Liang, Y., and Hetzer, M.W. 2011. Functional interactions between nucleoporins and chromatin. Curr.Opin. Cell. Biol. 23(1): 65-70. doi:10.1016/j.ceb.2010.09.008. PMID:21030234.

Limón, A., Nakajima, N., Lu, R., Ghory, H.Z., and Engelman, A. 2002. Wild-type levels of nuclear localization and human immunodeficiency virus type 1 replication in the absence of the central DNA flap. J.Virol. 76(23): 12078-86. doi:10.1128/JVI.76.23.1207812086.2002. PMID:12414949.

Llano, M., Delgado, S., Vanegas, M. and Poeschla, E. M. 2004a. LEDGF/p75 prevents proteasomal degradation of HIV-1 integrase. J. Biol. Chem. 279(53):55570-7. doi:10.1074/jbc.M408508200. PMID:15475359. 
898 Llano, M., Vanegas, M., Fregoso, O., Saenz, D., Chung, S., Peretz, M., and Poeschla, E.M. $8992004 b$. LEDGF/p75 determines cellular trafficking of diverse lentiviral but not murine 900 901 902 903 904 905 906 907 908 909 910 911 912 913 oncoretroviral integrase proteins and is a component of functional lentiviral preintegration complexes. J.Virol. 78(17): 9524-37. doi:10.1128/JVI.78.17.95249537.2004. PMID:15308744.

Lukic, Z., Dharan, A., Fricke, T., Diaz-Griffero, F., and Campbell, E.M. 2014. HIV-1 uncoating is facilitated by dynein and kinesin 1. J Virol. 88(23):13613-25. doi: 10.1128/JVI.0221914. PMID:25231297.

Maertens, G, Cherepanov, P, Debyser, Z, Engelborghs, Y, and Engelman, A. 2004. Identification and characterization of a functional nuclear localization signal in the HIV-1 integrase interactor LEDGF/p75. J Biol Chem.279(32): 33421-9. doi:10.1074/jbc.M404700200. PMID:15163664.

Maertens, G.N., Cook, N.J., Wang, W., Hare, S., Gupta, S.S., Öztop, I., Lee, K., Pye, V.E., Cosnefroy, O., Snijders, A.P., KewalRamani, V.N., Fassati, A., Engelman, A., and Cherepanov P. 2014. Structural basis for nuclear import of splicing factors by human Transportin 3. Proc. Natl. Acad. Sci. U.S.A.111(7):2728-33.

915 Matreyek, K.A., and Engelman A. 2011. The requirement for nucleoporin NUP153 during 916 human immunodeficiency virus type 1 infection is determined by the viral capsid. J.Virol. 85: 7818-27. doi:10.1128/JVI.00325-11. PMID:21593146.

918 Matreyek, K.A., and Engelman, A. 2013a. Viral and cellular requirements for the nuclear entry 919 of retroviral preintegration nucleoprotein complexes. Viruses, 5(10): 2483-2511. 920 doi:10.3390/v5102483. PMID:24103892. 
921 Matreyek, K.A., Yücel, S.S., Li, X., and Engelman, A. 2013b. Nucleoporin NUP153

922

923

924

925

926

927

928

929

930

931

932

933

934

935

936

937

938

939

940

941

942

943

phenylalanine-glycine motifs engage a common binding pocket within the HIV-1 capsid protein to mediate lentiviral infectivity. PLoS Pathog. 9(10): e1003693. doi:10.1371/journal.ppat.1003693. PMID:24130490.

McDonald, D., Vodicka, M.A., Lucero, G., Svitkina, T.M., Borisy, G.G., Emerman, M., and

Hope T.J. 2002. Visualization of the intracellular behavior of HIV in living cells. J. Cell. Biol. 159(3): 441-52. doi:10.1083/jcb.200203150. PMID:12417576.

Melchjorsen, J. 2013. Learning from the messengers: innate sensing of viruses and cytokine regulation of immunity - clues for treatments and vaccines. Viruses, 5(2): 470-527. doi:10.3390/v5020470. PMID:23435233.

Meng, Z., Zhang, X., Wu, J., Pei, R., Xu, Y., Yang, D., Roggendorf, M., and Lu, M. 2013.RNAi induces innate immunity through multiple cellular signaling pathways.PLoS One 8(5): e64708. doi:10.1371/journal.pone.0064708. PMID:23700487.

Monette, A., Panté, N., and Mouland, A.J. 2011. HIV-1 remodels the nuclear pore complex. J. Cell.Biol. 193(4): 619-31. doi:10.1083/jcb.201008064. PMID:21576391.

Moore, J.P., and Stevenson, M. 2000. New targets for inhibitors of hiv-1 replication. Nat. Rev. Mol. Cell. Biol. 1(1): 40-9.doi:10.1038/35036060. PMID:11413488.

Moroianu, J., Blobel, G., and Radu., A. 1996. Nuclear protein import, Ran- GTP dissociates the karyopherinalphabeta heterodimer by displacing alpha from an overlapping binding site on beta. Proc. Natl. Acad. Sci. U.S.A. 93(14):7059-7062. PMID:8692944.

Mulder, L.C., Chakrabarti, L.A., and Muesing, M.A. 2002. Interaction of HIV-1 integrase with DNA repair protein hRad18.J. Biol. Chem. 277(30): 27489-93. doi:10.1074/jbc.M203061200. PMID:12016221. 
944 Multhoff, G. 2007. Heat shock protein 70 (Hsp70), membrane location, export 945 immunological relevance. Methods, 43(3): 229-37. doi:10.1016/j.ymeth.2007.06.006. 946 PMID:17920520.

947 Nardozzi, J.D., Lott, K., and Cingolani, G. 2010. Phosphorylation meets nuclear import, a 948 review. Cell.Commun. Signal, 8: 32. doi:10.1186/1478-811X-8-32. PMID:21182795.

949 Nitahara-Kasahara, Y., Kamata, M., Yamamoto, T., Zhang, X., Miyamoto, Y., Muneta, K., 950 Iijima, S., Yoneda, Y., Tsunetsugu-Yokota, Y., and Aida, Y. 2007. Novel nuclear import of Vpr promoted by importin alpha is crucial for human immunodeficiency virus type 1 replication in macrophages. J.Virol. 81(10): 5284-93. doi:10.1128/JVI.01928-06.

954 955 956 957 958 959 960 961 962 963 964 965 966 PMID:17344301.

Ocwieja, K.E., Brady, T.L., Ronen, K., Huegel, A., Roth, S.L., Schaller, T., James, L.C., Towers, G.J., Young, J.A., Chanda, S.K., König, R., Malani, N., Berry, C.C., and Bushman, F.D. 2011. HIV integration targeting, a pathway involving Transportin-3 and the nuclear pore protein RanBP2. PLoS Pathog. 7(3): e1001313. doi:10.1371/journal.ppat.1001313. PMID:21423673.

Okuno, Y., Imamoto, N., and Yoneda, Y. 1993. 70-kDa heatshock cognate protein colocalizes with karyophilic proteins into the nucleus during their transport in vitro. Exp. Cell. Res. 206(1): 134-42. doi:10.1006/excr.1993.1129. PMID:8482354.

Overbaugh, J., Miller, A.D., and Eiden, M.V. 2001. Receptors and entry cofactors for retroviruses include single and multiple transmembrane-spanning proteins as well as newly described glycophosphatidyl inositol-anchored and secreted proteins. Microbiol. Mol. Biol. Rev. 65(3): 371-389. doi:10.1128/MMBR.65.3.371-389.2001. PMID:11528001. 
967 968 969 970 971 972 973 974 975 976 977 978 979 980 981 982 983 984 985 986 987 988 989

Palmeri, D., and Malim, M.H. 1999. Importin beta can mediate the nuclear import of an arginine rich nuclear localization signal in the absence of importin alpha. Mol. Cell. Biol. 19(2): 1218-25. PMID:9891056.

Pante, N., and Kann, M. 2002. Nuclear pore complex is able to transport macromolecules with diameters of about $39 \mathrm{~nm}$. Mol. Biol. Cell, 13(2): 425-434. doi:10.1091/mbc.01-06-0308. PMID:11854401.

Patton, G.S., Erlwein, O., and McClure, M.O. 2004. Cell-cycle dependence of foamy virus vectors. J. Gen.Virol. 85(Pt 10): 2925-30. doi:10.1099/vir.0.80210-0. PMID:15448354.

Paulillo, S.M., Phillips, E.M., Köser, J., Sauder, U., Ullman, K.S., Powers, M.A., and Fahrenkrog, B. 2005. Nucleoporin domain topology is linked to the transport status of the nuclear pore complex. J. Mol. Biol. 351(4): 784-98. doi:10.1016/j.jmb.2005.06.034. PMID:16045929.

Petit, C., Schwartz, and O.Mammano, F. 2000. The karyophilic properties of human immunodeficiency virus type 1 integrase are not required for nuclear import of proviral DNA. J. Virol. 74(15): 7119-7126. doi:10.1128/JVI.74.15.7119-7126.2000. PMID:10888652.

Porter, F.W., and Palmenberg. A.C. 2009. Leader-induced phosphorylation of nucleoporins correlates with nuclear trafficking inhibition by cardioviruses. J. Virol. 83(4): 1941-1951. doi:10.1128/JVI.01752-08. PMID:19073724.

Price, A.J., Fletcher, A.J., Schaller, T., Elliott, T., Lee, K., KewalRamani, V.N., Chin, J.W., Towers, G.J., and James, L.C. 2012. CPSF6 defines a conserved capsid interface that modulates HIV-1 replication. PLoS Pathog. 8(8): e1002896. doi:10.1371/journal.ppat.1002896. PMID:22956906. 
990 Price, A.J., Jacques, D.A., McEwan, W.A., Fletcher, A.J., Essig, S., Chin, J.W., Halambage, 991 U.D., Aiken, C., and James, L.C. 2014. Host cofactors and pharmacologic ligands share 992 an essential interface in HIV-1 capsid that is lost upon disassembly. PLoS Pathog. 10(10): 993 e1004459. doi:10.1371/journal.ppat.1004459. PMID:25356722.

994 Randow, F., MacMicking, J.D., and James, L.C. 2013. Cellular self-defense, how cell995 autonomous immunity protects against pathogens. Science, 340(6133): 701-6. 996 doi:10.1126/science.1233028. PMID:23661752.

997 Reil, H., Bukovsky, A.A., Gelderblom, H.R., and Göttlinger, H.G. 1998. Efficient HIV-1 998 replication can occur in the absence of the viral matrix protein. EMBO J. 17 (9): 2699999 708. doi: 10.1093/emboj/17.9.2699. PMID:9564051.

Rüegsegger, U., Blank, D., and Keller, W. 1998. Human pre-mRNA cleavage factor Im is related 1001 to spliceosomal SR proteins and can be reconstituted in vitro from recombinant subunits. Mol. Cell, 1(2): 243-53. doi:10.1016/S1097-2765(00)80025-8. PMID:9659921.

Schaller, T., Ocwieja, K.E., Rasaiyaah, J., Price, A.J., Brady, T.L., Roth, S.L., Hué, S., Fletcher, 1004 1005 A.J., Lee, K., KewalRamani, V.N., Noursadeghi, M., Jenner, R.G., James, L.C., Bushman, F.D., and Towers, G.J. 2011. HIV-1 capsid-cyclophilin interactions determine nuclear import pathway, integration targeting and replication efficiency. PLoS Pathog, 7(12): e1002439. doi:10.1371/journal.ppat.1002439. PMID:22174692.

Schmitz, A., Schwarz, A., Foss, M., Zhou, L., Rabe, B., Hoellenriegel, J., Stoeber, M., Panté, N., and Kann, M. 2010. Nucleoporin 153 arrests the nuclear import of hepatitis B virus 1010 capsids in the nuclear basket. PLoSPathog. 6(1): e1000741. 1011 doi:10.1371/journal.ppat.1000741. PMID:20126445. 
1012 Segura-Totten, M., and Wilson, K.L. 2004. BAF, roles in chromatin, nuclear structure and

1013

1014

1015

1016

1017

1018

1019

1020

1021

1022

1023

1024

1025

1026

1027

1028

1029

1030

1031

1032

1033

1034 retrovirus integration. Trends Cell. Biol. 14(5): 261-6. doi:10.1016/j.tcb.2004.03.004. PMID:15130582.

Serhan, F., Penaud, M., Petit, C., Leste-Lasserre, T., Trajcevski, S., Klatzmann, D., Duisit, G., Sonigo, P., and Moullier, P. 2004. Early detection of a twolong-terminal-repeat junction molecule in the cytoplasm ofrecombinant murine leukemia virus-infected cells. J Virol, 78(12): 6190-6199. doi:10.1128/JVI.78.12.6190-6199.2004. PMID:15163712.

Shah, V.B., Shi, J., Hout, D.R., Oztop, I., Krishnan, L., Ahn, J., Shotwell, M.S., Engelman, A., and Aiken, C. 2013. The host proteins transportin SR2/TNPO3 and cyclophilin A exert opposing effects on HIV-1 uncoating. J.Virol. 87(1): 422-32. doi:10.1128/JVI.07177-11. PMID:23097435.

Sirven, A., Pflumio, F., Zennou, V., Titeux, M., Vainchenker, W., Coulombel, L., DubartKupperschmitt, A., and Charneau, P. 2000. The human immunodeficiency virus type-1 central DNA flap is a crucial determinant for lentiviral vector nuclear import and gene transduction of human hematopoietic stem cells. Blood, 96(13): 4103-10. PMID:11110680.

Sloan, R.D., and Wainberg, M.A. 2011. The role of unintegrated DNA in HIV infection. Retrovirology, 8: 52. doi:10.1186/1742-4690-8-52. PMID:21722380.

Stewart, M. 2007. Molecular mechanism of the nuclear protein import cycle. Nat. Rev. Mol. Cell. Biol. 8(3): 195-208. doi:10.1038/nrm2114. PMID:17287812.

Sticht, J., Humbert, M., Findlow, S., Bodem, J., Muller, B., Dietrich, U., Werner, J., and Krausslich, H.G. 2005. A peptide inhibitor of HIV-1 assembly in vitro. Nat. Struct. Mol. Biol. 12: 671-677. PMID:16041387. 
1035 Strebel, K. 2003. Virus-host interactions, role of HIV proteins Vif, Tat, and Rev. AIDS.17:

1036

1037

1038

1039

1040

1041

1042

1043

1044

1045

1046

1047

1048

1049

1050

1051

1052

1053

1054

1055

1056

1057 S25-34. PMID:15080177.

Suzuki, Y., and Craigie, R. 2007. The road to chromatin - nuclear entry of retroviruses. Nat. Rev. Microbiol. 5(3):187-96. doi:10.1038/nrmicro1579. PMID:17304248.

Trotman, L.C., Mosberger, N., Fornerod, M., Stidwill, R.P., and Greber. U.F. 2001. Import of adenovirus DNA involves the nuclear pore complex receptor CAN/Nup214 and histone H1. Nat. Cell. Biol. 3(12): 1092-1100. doi:10.1038/ncb1201-1092. PMID:11781571.

Truant, R., and Cullen, B.R. 1999. The arginine rich domains present in human immunodeficiency virus type 1 tat and rev function as direct importin beta-dependent nuclear localization signals. Mol. Cell. Biol. 19(2): 1210-17. PMID:9891055

Tsurutani, N., Kubo, M., Maeda, Y., Ohashi, T., Yamamoto, N., Kannagi, M., and Masuda, T. 2000. Identification of critical amino acid residues in human immunodeficiency virus type 1 IN required for efficient proviral DNA formation at steps prior to integration in dividing and nondividing cells. J. Virol. 74(10): 4795-806. PMID:10775618.

Valle-Casuso, J.C., Di Nunzio F., Yang, Y., Reszka N., Lienlaf, M., Arhel, N., Perez, P., Brass, A.L., and Diaz-Griffero F. 2012. TNPO3 is required for hiv-1 replication after nuclear import but prior to integration and binds the HIV-1 core. J.Virol. 86(10): 5931-6. doi:10.1128/JVI.00451-12. PMID:22398280.

Varadarajan, P., Mahalingam, S., Liu, P., Ng, S.B., Gandotra, S., Dorairajoo, D.S., $\quad$ and Balasundaram, D. 2005. The functionally conserved nucleoporins Nup124p from fission yeast and the human Nup153 mediate nuclear import and activity of the Tf1 retrotransposon and HIV-1 Vpr. Mol. Biol. Cell, 16(4): 1823-1838. doi: 10.1091/mbc.E04-07-0583. PMID:15659641. 
1058 Walker, B., and McMichael, A. 2012. The T-cell response to HIV. 2(11). pii: a007054. 1059 doi:10.1101/cshperspect.a007054. PMID:23002014.

1060 Walther, T.C., Pickersgill, H.S., Cordes, V.C., Goldberg, M.W., Allen, T.D., Mattaj, I.W., 1061 and Fornerod, M. 2002. The cytoplasmic filaments of the nuclear pore complex are 1062 dispensable for selective nuclear protein import. J. Cell. Biol. 158(1): 63-77. 1063 doi:10.1083/jcb.200202088. PMID:12105182

1064 Whitehead, K.A., Dahlman, J.E., Langer, R.S., and Anderson, D.G. 2011. Silencing or 1065 stimulation? siRNA delivery and the immune system. Annu. Rev. Chem.Biomol. Eng. 2: 771066 96. doi:10.1146/annurev-chembioeng-061010-114133. PMID:22432611.

1067 Woodward, C.L., Prakobwanakit, S., Mosessian, S., and Chow, S.A. 2009. Integrase interacts 1068 1069 with nucleoporin NUP153 to mediate the nuclear import of human immunodeficiency virus type 1. J.Virol. 83(13): 6522-33. doi:10.1128/JVI.02061-08. PMID:19369352.

1070 Xu, H., Franks, T., Gibson, G., Huber, K., Rahm, N., Strambio De Castillia, C., Luban, J., Aiken, 1071 C., Watkins, S., Sluis-Cremer, N., and Ambrose, Z. 2013. Evidence for biphasic 1072 uncoating during HIV-1 infection from a novel imaging assay. Retrovirology. 10:70. doi: 1073 10.1186/1742-4690-10-70. PMID:23835323.

1074 Yamashita, M., and Emerman, M. 2004. Capsid is a dominant determinant of retrovirus 1075 infectivity in nondividing cells. J. Virol.78(11): 5670-8. doi:10.1128/JVI.78.11.56701076 5678.2004. PMID:15140964.

1077 Ylinen, L.M., Schaller, T., Price, A., Fletcher, A.J., Noursadeghi, M., James, L.C., and Towers, 1078 G.J. 2009.Cyclophilin A levels dictate infection efficiency of human immunodeficiency 1079 virus type 1 capsid escape mutants A92E and G94D. J.Virol. 83(4): 2044-7. 1080 doi:10.1128/JVI.01876-08. PMID:19073742. 
1081 Yung, E., Sorin, M., Pal, A., Craig, E., Morozov, A., Delattre, O., Kappes, J., Ott, D., and 1082 Kalpana, G.V. 2001. Inhibition of HIV-1 virion production by a transdominant mutant of 1083 integrase interactor 1. Nat. Med. 7(8): 920-6. doi:10.1038/90959. PMID:11479624.

1084 Zennou, V., Petit, C., Guetard, D., Nerhbass, U., Montagnier, L., and Charneau, P. 2000. HIV-1 1085 genome nuclear import is mediated by a central DNA flap. Cell, 101(2): 173-85. 1086 doi:10.1016/S0092-8674(00)80828-4. PMID:10786833.

1087 Zhang, R., Mehla, R., and Chauhan, A. 2010. Perturbation of host nuclear membrane component 1088 RanBP2 impairs the nuclear import of human immunodeficiency virus -1 preintegration 1089 complex (DNA). PLoS One, 5(12): e15620. doi:10.1371/journal.pone.0015620. $1090 \quad$ PMID:21179483.

1091 Zielske, S.P., and Stevenson, M. 2005. Importin 7 may be dispensable for human 1092 immunodeficiency virus type 1 and simian immunodeficiency virus infection of 1093 primary macrophages. J. Virol. 79(17): 11541-6. doi:10.1128/JVI.79.17.115411094 11546.2005. PMID:16103209.

1095 Zolotukhin, A.S., and Felber, B.K. 1999. Nucleoporins nup98 and nup214 participate in nuclear 1096 export of human immunodeficiency virus type 1 Rev. J.Virol. 73(1): 120-7. 1097 PMID:9847314.

1098 


\section{Figure legends}

Fig. 1. Model for early events of the retroviral life cycle. Early events of HIV-1 replication

1104 include fusion to the CD4 receptor on the cell membrane and entry. Subsequently, capsid 1105 removal or uncoating occurs, followed by reverse transcription of the viral RNA to cDNA or 1106 reverse transcripts, and production of the reverse transcription complex (RTC) with other viral 1107 proteins. These reverse transcripts either undergo recombination to form circular DNA, or form a 1108 pre-integration complex (PIC) through association with different cellular proteins. The complex 1109 moves along the cytoskeleton through the cytoplasm and enters the nucleus through the nuclear 1110 pore complex (NPC), where viral protein integrase (IN) incorporates the viral cDNA to form 1111 integrated DNA or proviruses.

1113 Fig. 2. Cell-cycle dependent retroviral nuclear entry. (A) Entry of HIV-1 and simian 1114 immunodeficiency virus (SIV) through NPC into the nuclei of non-dividing cells and integration 1115 into the host genome. (B) Entry of murine leukemia virus (MLV) and foamy viruses such as 1116 prototype foamy virus (PFV) and feline foamy virus (FFV) into the nuclei of dividing cells. a. 1117 dissociation of nuclear membrane and access of PIC to cellular genomic DNA, followed by 1118 integration. b. Initiation of nuclear division and separation of the provirus-containing host 1119 genome. (C) Formation of two daughter nuclei containing integrated viral DNA.

1121 Fig. 3. Competition of different components interacting with the HIV-1 capsid and their role in 1122 CA stabilization and nuclear entry. (A) Cyclophilin A (cyp A) and the drug CAI can bind 
1123 competitively with the capsid pocket to destabilize CA, resulting in premature release of viral 1124 RNA and inhibition of nuclear entry. (B) Cellular protein cleavage and polyadenylation specific 1125 factor 6 (CPSF6) and small molecule inhibitors such as PF-3450074 (PF74) and BI-2 compete 1126 for binding to CA, stabilizing the CA lattice to delay release of the viral genetic material, thereby 1127 resulting in impaired nuclear entry. 

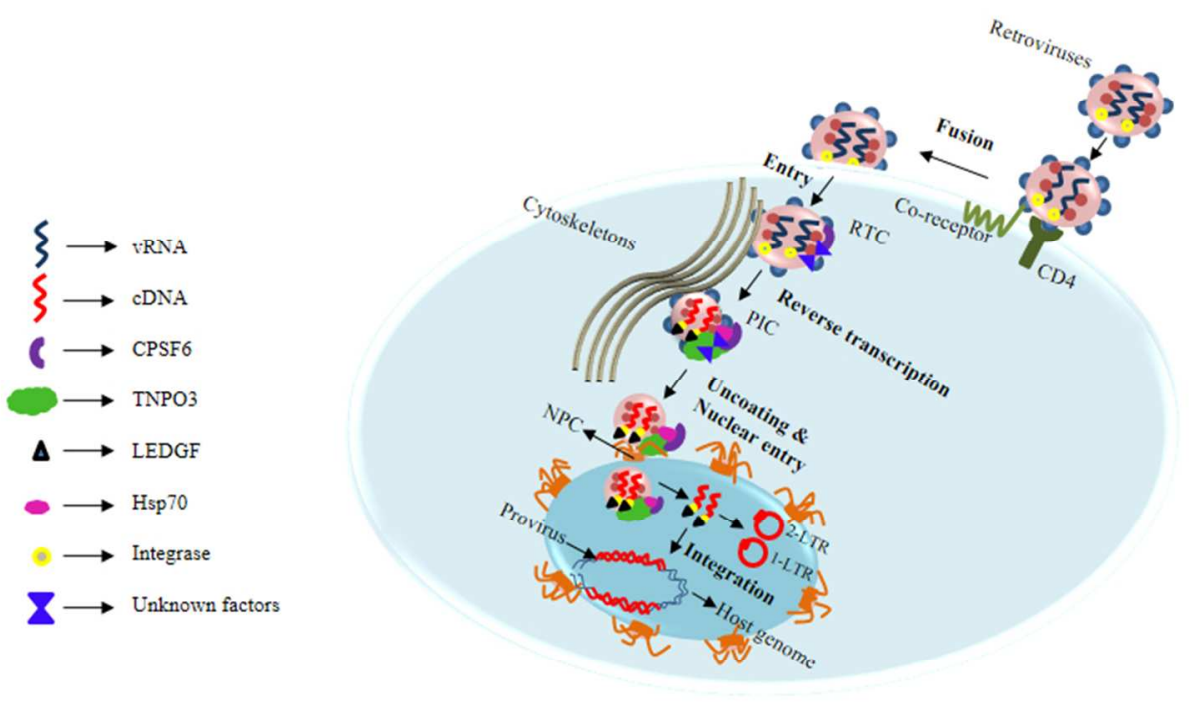

Fig 1

$215 \times 254 \mathrm{~mm}(96 \times 96 \mathrm{DPI})$ 
A.

B.

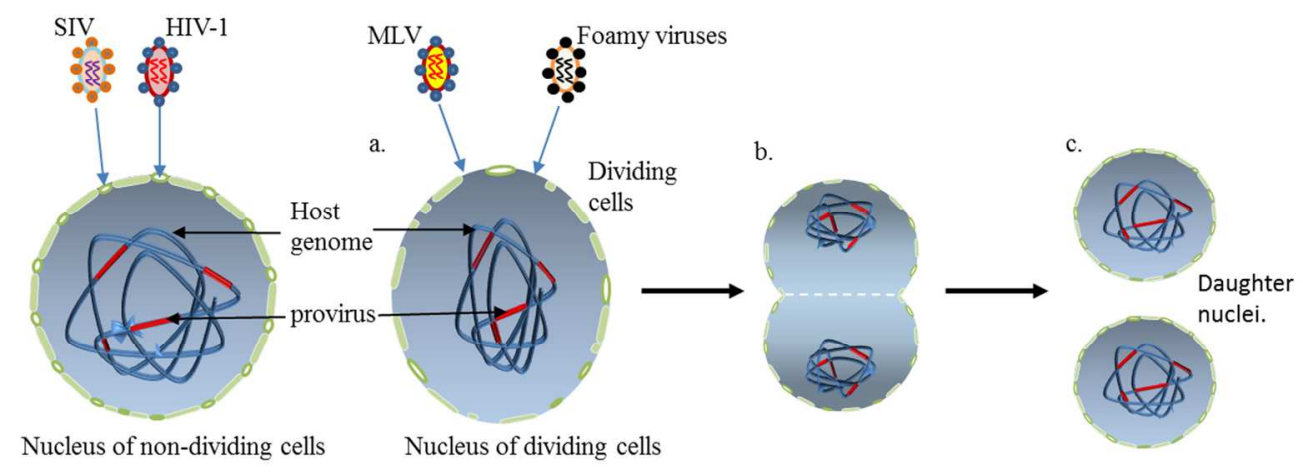

Fig 2

$214 \times 87 \mathrm{~mm}(300 \times 300$ DPI $)$ 
A. Destabilization

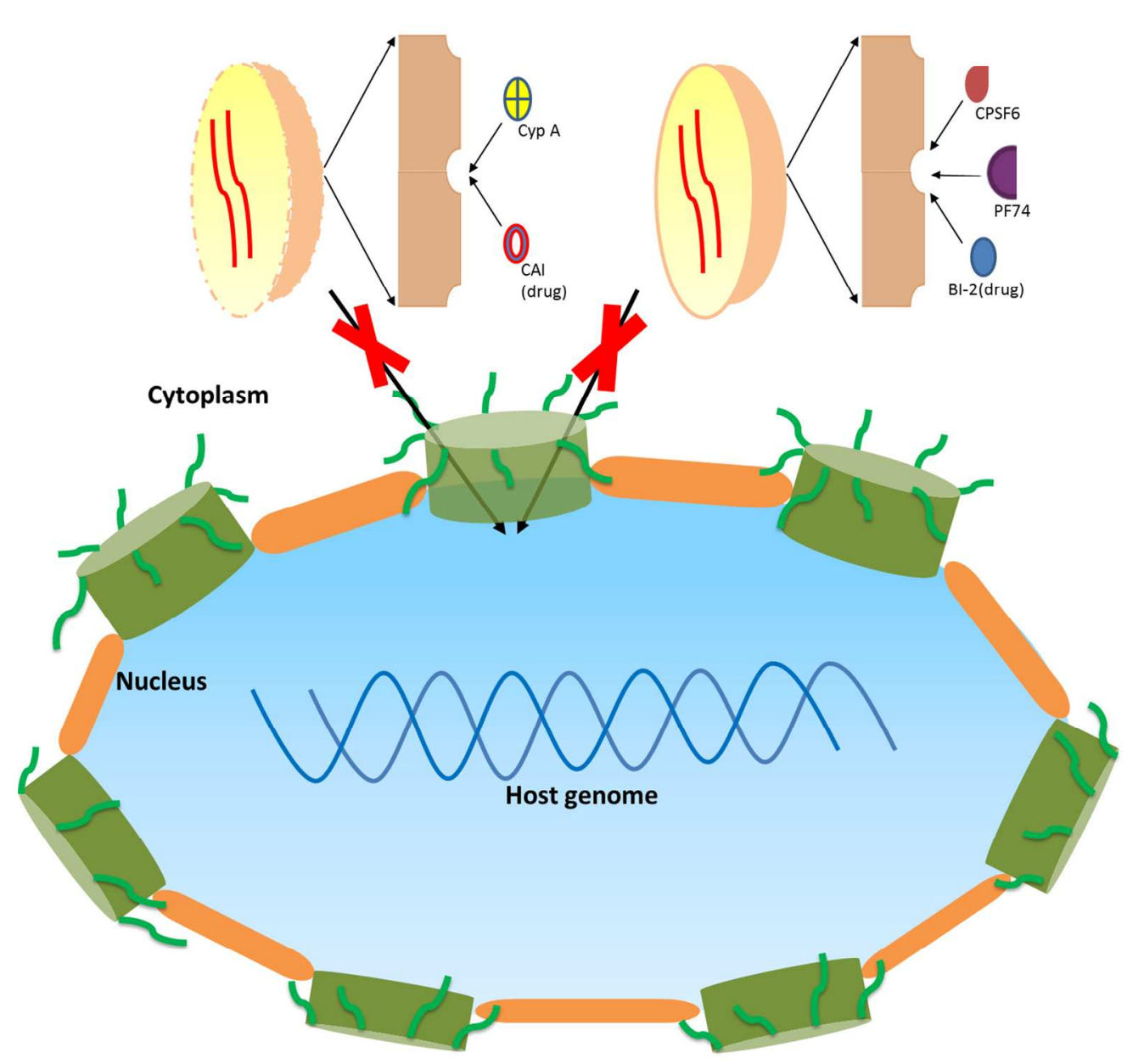

Fig 3

$252 \times 252 \mathrm{~mm}(300 \times 300$ DPI $)$

B. Stabilization 